Chapman University

Chapman University Digital Commons

ESI Working Papers

Economic Science Institute

2015

\title{
Revisiting the Tradeoff between Risk and Incentives: The Shocking Effect of Random Shocks
}

Brice Corgnet

Chapman University, corgnet@chapman.edu

Roberto Hérnan-Gonzalez

University of Nottingham

Follow this and additional works at: http://digitalcommons.chapman.edu/esi_working_papers

Part of the Econometrics Commons, Economic Theory Commons, and the Other Economics Commons

\section{Recommended Citation}

Corgnet, B., \& Hernán-González, H. (2015). Revisiting the tradeoff between risk and incentives: The shocking effect of random shocks. ESI Working Paper 15-05. Retrieved from http://digitalcommons.chapman.edu/esi_working_papers/154

This Article is brought to you for free and open access by the Economic Science Institute at Chapman University Digital Commons. It has been accepted for inclusion in ESI Working Papers by an authorized administrator of Chapman University Digital Commons. For more information, please contactlaughtin@chapman.edu. 


\title{
Revisiting the Tradeoff between Risk and Incentives: The Shocking Effect of Random Shocks
}

\author{
Comments \\ Working Paper 15-05
}




\title{
Revisiting the Tradeoff between Risk and Incentives: The Shocking Effect of Random Shocks
}

\author{
Brice Corgnet (Chapman University) \\ Roberto Hernan-Gonzalez (University of Nottingham)
}

\begin{abstract}
Despite its central role in the theory of incentives, empirical evidence of a tradeoff between risk and incentives remains scarce. We reexamine this empirical puzzle in a controlled laboratory environment so as to isolate possible confounding factors encountered in the field. In line with the principal-agent model, we find that principals increase fixed pay while lowering performance pay when the relationship between effort and output is noisier. Unexpectedly, agents produce substantially more in the noisy environment than in the baseline despite lesser pay for performance. We show that this result can be accounted for by introducing agents' loss aversion in the principal-agent model. Our findings call for an extension of standard agency models and for a reassessment of apparently inefficient management practices.
\end{abstract}

KEYWORDS: Principal-agent models, incentive theory, loss aversion, laboratory experiments. JEL CODES: C92, D23, D86, M54.

\section{INTRODUCTION}

One of the building blocks of the economic theory of incentives is the tradeoff between risk and incentives in principal-agent models (Stiglitz, 1974; Holmström, 1979). Risk-neutral principals are expected to hedge risk-averse agents by offering them a contract with less pay for performance but a higher fixed pay when the relationship between effort and output is noisier. Despite its central role in the theory of incentives, there is scarce evidence that such tradeoff between risk and incentives prevails (Garen, 1994; Prendergast, 2002). If anything, studies have reported evidence of a positive rather than negative relationship between risk and incentives. Accounting for this positive relationship led to a new wave of theoretical models (Zabojnik, 1996; Prendergast, 2002; Baker and Jorgensen, 2003; Raith 2008; Edmans and Gabaix, 2011; He

\footnotetext{
* We thank Isabelle Brocas, Antonio Cabrales, Juan Carrillo, Gary Charness, Ramon Cobo-Reyes, Cary Deck, David Dickinson, Mari Paz Espinosa, Glenn Harrison, Natalia Jimenez, Steve Rassenti, Joshua Tasoff and seminar participants at various institutions for helpful comments. We also thank the Economic Science Institute and Chapman University for their generous support. Any remaining errors are ours.
} 
et al., 2014). The lack of support for the tradeoff between risk and incentives is likely due to the many confounds arising when testing this result in the field as well as the limited information available regarding workers' and managers’ risk attitudes. Prendergast (2002) puts forward the delegation of authority to the agent as one of the possible confounding factors. He argues that principals are more likely to delegate decision making to agents when uncertainty is prevalent which in turn may lead to more performance pay and a positive correlation between risk and incentives. This conjecture was empirically supported in the works of Adams (2005) and DeVaro and Kurtulus (2010).

Instead of inquiring on the moderating factors in the tradeoff between risk and incentives, we propose to isolate these possible confounds by studying the relationship between risk and incentives in a controlled laboratory environment. As is argued in Lazear and Oyer (2013), the lack of support for the trade-off between risk and incentives is “...at least partially due to an inability to make 'everything else equal'”. Making everything else equal is a definitive advantage of the experimental approach (Falk and Fehr, 2003; Charness and Kuhn, 20110; Camerer and Weber, 2012). Another decisive advantage of laboratory experiments is to allow for a direct measurement of individual risk attitudes.

We thus design a virtual workplace that provides an ecologically rich, yet controlled, environment for studying incentive setting in the lab (Corgnet, Hernan-Gonzalez and Schniter, 2014). We believe our experimental design responds to the call "to design empirical strategies and measures that can confirm or refute (...) the basic moral hazard model.” (Lazear and Oyer, 2013). In this environment, agents can work on a task which resembles a real-world clerical job (summing numbers in a table) or shirk (browsing the web). Our experimental design recreates the main features of the standard principal-agent model in which the principal offers a linear contract to the agent, which includes a fixed pay as well as a share of the agent's production. The agent then decides whether to accept or reject the principal's offer. In case of acceptance, the agent is rewarded according to the agreed-upon contract. In case of rejection, the agent is given an outside payment. We consider two treatments which only differ in the relationship between the agent's effort and output. This relationship is deterministic in the baseline treatment and is stochastic in the noise treatment. In line with the standard tradeoff between risk and incentives, we find that principals reduce performance pay while increasing fixed pay in the noisy environment compared to the baseline. In line with this finding, we show that principals are more inclined to hedge agents against risk when they are perceived to be more risk averse. 
Unexpectedly, we find that, in sharp contrast with the theoretical predictions of the principalagent model, agents exert more effort and produce significantly more in the noisy environment than in the baseline despite lesser pay for performance. We show that this striking result can be accounted for by introducing agents' loss aversion in the standard principal-agent model. In this model, principals hedge agents against losses by reducing performance pay similarly to the classical tradeoff between risk and incentives. In this model, however, loss-averse agents may exert more effort in the noisy environment than in the baseline despite weaker incentives. This is the case because loss-averse agents strive to avoid the losses that follow from the realization of negative shocks. We find direct support for the loss aversion model by showing that, in our experimental setting with noise, loss-averse agents increase their production after incurring losses. This positive effect of loss aversion on work performance is consistent with previous research studying the effect of framing incentives as either "gains" or "losses” (e.g. Fryer et al. 2012; Hossain and List, 2012). These field experiments show that framing incentives as "losses" (punishments) leads to higher performance of teachers (Fryer et al. 2012) and manufacturing workers and supervisors (Hossain and List, 2012) than framing incentives as "gains” (rewards). These results contrast with standard agency theory which would predict a null framing effect. Our findings contrast even further with standard agency theory as they contradict the prediction that agents should exert less effort in the noisy environment.

The increase in agents' production in the noisy environment also implies an increase in principals’ profits. More generally, this suggests that principals may benefit from designing work environments and labor contracts that induce high levels of risk and uncertainty. This observation echoes a growing body of research that shed light on the positive implications of contractual opacity on work performance (e.g. Bernheim and Whinston, 1998; Ederer, Holden and Mayers, 2014; Jehiel, 2014). These works, however, do not incorporate loss aversion reflecting instead on the importance of information asymmetry and verifiability. Our findings hinge upon the behavioral assumption of loss aversion and thus do not rely on the completeness of the contractual setting or on the distribution of information across parties.

Our findings suggest that recognizing the motivational effect of loss aversion in risky environments may alter the conclusions of agency models in a broad range of contractual settings. Our work also calls for a reevaluation of the well-accepted and influential expectancy theory of motivation (Vroom, 1964) according to which workers are expected to exert higher effort in contractual environments that closely tie effort to performance. 


\section{THEORETICAL FRAMEWORK}

Our analysis builds on the LEN (linear exponential normal) principal-agent model which has been widely used for its tractability (Milgrom and Roberts, 1992; Laffont and Martimort, 2002; Bolton and Dewatripont, 2005; Besanko et al. 2012; Gibbons and Roberts, 2013). In this model, the principal is assumed to be risk neutral while the agent is assumed to be risk averse. The risk neutrality of the principal is typically justified by the possibility to diversify risk by allocating resources to various employees and projects.

In this setting, the principal first proposes a linear contract to the agent $(\alpha, \beta)$ where $\alpha$ and $\beta$ represent the fixed pay and the share of total output $(z)$ that will be paid to the agent. The agent then decides whether to accept or reject the contract in which case he would receive an outside payment $\left(v_{0}\right)$. In case the agent accepts the contract, he exerts a level of effort $(e)$. Even though the principal cannot observe the level of effort of the agent, she can observe the output of effort, $z=e+x$, where $x \sim N\left(0, \sigma^{2}\right)$. After observing $z$, the principal pays the agent $(y)$ according to the terms of the contract so that: $y=\alpha+\beta z$. The principal maximizes expected payoffs $E(\theta z-y)$, where $\theta$ represents the value for the principal of each unit of output. The agent maximizes his expected utility which is assumed to be exponential: $U(y, e)=-e^{-r[y-C(e)]}$, where $C(e)$ is the cost of effort function, $C^{\prime}()>$.0 and $C^{\prime \prime}()>$.0 , and $r$ is the coefficient of absolute risk aversion. In this model, maximizing the utility function of the agents amounts to

maximizing his certainty equivalent: $\alpha+\beta e-C(e)-\frac{1}{2} r \beta^{2} \sigma^{2}$ (e.g. Milgrom and Roberts, 1992).

One important implication of the model is the existence of a tradeoff between risk and the intensity of incentives provided by the principal $(\beta)$. An increase in $\beta$ incentivizes the agent to work harder as it increases the weight of performance pay in the contract, however, it also increases the variance of the agent's pay. The optimal contract is for the principal to select an intermediate value of $\beta$ that incentivizes the agent to exert effort while not inducing an unbearable amount of risk. As a result, the presence of noise in the evaluation of the agent's performance $\left(\sigma^{2}>0\right)$ leads the principal to decrease $\beta$ while increasing fixed pay $(\alpha)$ so as to provide insurance to the agent. Also, managers will propose contracts with lower risk levels (a lower $\beta$ and a higher $\alpha$ ) to agents who are perceived to be more risk averse (higher $r$ ).

The two key predictions of the model are the existence of "incentives effects" and the "tradeoff between risk and incentives” (Lazear and Oyer, 2013). We summarize these conjectures below. 


\section{Hypothesis 1 (Tradeoff between risk and incentives)}

a) We expect principals to offer a lower share of production and a higher fixed pay in the presence of noise than in its absence.

b) In the presence of noise, we expect principals to offer a lower share of production and a higher fixed pay when they perceive agents to be risk averse than when they do not.

Given that principals pay a lower share of production to agents in the presence of noise, the standard LEN principal-agent model predicts that agents will produce less in the presence of noise $\left(\sigma^{2}>0\right)$ than in its absence $\left(\sigma^{2}=0\right)$.

\section{Hypothesis 2 (Incentives effects)}

We expect agents to exert less effort and produce less in the presence of noise than in its absence.

\section{EXPERIMENTAL DESIGN}

\subsection{Virtual Workplace with Real Effort and Real Leisure}

We develop a framework in which subjects can undertake a real-effort task while having access to a real-leisure alternative (browsing the Internet) at any point in time during the experiment. The idea is to construct a laboratory environment in which on-the-job shirking is commonly observed so as to be able to uncover subtle incentives effects (Corgnet, HernanGonzalez and Schniter, 2014).

The laboratory setting allows the experimenter to control for possible confounding factors commonly encountered in the field such as organizational hierarchies or implicit incentives. The experimental environments will only vary on the noisiness of the relationship between effort and output. The work task, the incentive schemes and the stakes will remain constant across treatments.

\subsubsection{Organizational Roles}

We consider two types of subjects referred to as B (agent) and C (principal). At the beginning of each of the 6 periods, subjects were randomly assigned to one of these two roles. As a result, subjects could either be an agent or a principal depending on the period. Each agent was randomly matched with a single principal. During a period, agents could dedicate their time to 
either completing the work task or browsing the web while principals could only browse the Internet.

\subsubsection{The Work Task}

We consider a real-effort summation task that is particularly long and effortful (e.g. Niederle and Vesterlund (2007); Eriksson, Poulsen and Villeval (2009); Dohmen and Falk (2011)). Subjects would sum up matrices of 36 numbers comprised between 0 and 3 for one hour, divided into 10-minute periods, with no breaks in between. Each table completed correctly generated 40cent of agent's production $(z)$ while a penalty of 20 cents was subtracted from the agent's production for each incorrect answer. ${ }^{1}$

Subjects were not allowed to use a pen, scratch paper or calculator. This rule amplified the level of effort subjects had to exert in order to complete the task correctly. Our work task was designed to reduce as much as possible the intrinsic motivation derived from the task itself. An example of the work task is shown in Figure 1.

\begin{tabular}{|c|c|c|c|c|c|c|}
\hline & Column1 & Column2 & Column3 & Column 4 & Column5 & Column6 \\
\hline & 3.00 & 0.00 & 0.00 & 2.00 & 3.00 & 0.00 \\
\hline & 2.00 & 3.00 & 3.00 & 2.00 & 1.00 & 1.00 \\
\hline & 1.00 & 1.00 & 2.00 & 0.00 & 0.00 & 1.00 \\
\hline & 3.00 & 0.00 & 0.00 & 1.00 & 1.00 & 2.00 \\
\hline & 1.00 & 3.00 & 0.00 & 3.00 & 2.00 & 1.00 \\
\hline & 1.00 & 3.00 & 1.00 & 1.00 & 2.00 & 3.00 \\
\hline Sum Column: & & & & & & \\
\hline
\end{tabular}

FIGURE 1.- Example of table summation for the work task.

\subsubsection{Internet Browsing}

At any point during the experiment, agents could switch from the work task to the leisure activity that consisted of browsing the Internet. Each activity was undertaken separately, in a different screen so that subjects could not sum tables while being on the Internet. Subjects were informed that their use of the Internet was strictly confidential. Subjects were free to consult their email or visit any web page. ${ }^{2}$ The Internet browser was embedded in the software so that the experimenter could keep record of the exact amount of time subjects spent on each activity.

\subsubsection{Contracts}

At the beginning of each period, principals were endowed with 200థ. Principals had to propose a linear contract to the agent by offering a non-negative fixed pay ( $\alpha$ ) (in the limit of their 200屯 endowment) as well as a share $(\beta)$ of the agent's production. Because the fixed pay cannot be

\footnotetext{
${ }^{1}$ Penalties did not apply when individual production was equal to zero so that individual production could not be negative.

${ }^{2}$ Subjects were expected to follow the norms set by the university regarding the use of Internet on campus.
} 
negative, the agent cannot transfer money to the principal. ${ }^{3}$ Agents could either accept or reject the offer. In case of acceptance, the agent would be rewarded according to the agreed-upon contract. The agent would then be able to work on the task or browse the Internet for leisure purposes. In case of rejection, the agent would only be able to browse the web for a fixed payment of $150 \$$ and the principal would keep his or her initial endowment of $200 \AA$.

\subsection{Treatments}

We conducted two treatments. The earnings for the agent and the principal in the baseline and noise treatments were computed as described in Table 1. In both treatments, if the agent rejects the principal’s offer, the agent receives $150 \$$ and the principal receives $200 \AA$. If the agent accepts the offer, the principal receives a fixed pay as well as a variable pay. The principal's fixed pay is equal to her initial endowment minus the fixed pay offered to the agent $(200-\alpha)$. The variable pay is equal to the share of the agent's production the principal kept for herself $((1-\beta) \times($ Agent production)).

The earnings of the agent differ across treatments. In the noise treatment, the agent's earnings are affected by an additive random Shock that takes values $-100 \notin$ or $+100 \notin$ with equal chances. ${ }^{4}$ The magnitude of the Shock is equivalent to 2.5 correct tables which corresponds to about 30\% of the agent's production level in the baseline treatment. The principal, however, was not affected by the Shock in the noise treatment so as to induce risk-neutrality (Smith, 1976).The risk neutrality of the principal is a standard assumption in the LEN model which we do not test in the current design. Instead, we chose to induce risk neutrality and study the prediction of the model regarding risk sharing between the principal and the agent (Hypothesis 1). ${ }^{5}$

TABLE 1. Earnings computation (in cents) in the baseline and noise treatments in case the principal's offer $(\alpha, \beta)$ is accepted by the agent.

\begin{tabular}{ccc}
\hline \hline Treatment & Agents’ period earnings & Principals’ period earnings \\
\hline Baseline & $\alpha+\beta \times($ Agent production $)$ & $(200-\alpha)+(1-\beta) \times($ Agent production $)$ \\
\hline Noise & $\alpha+\beta \times($ Agent production $+/-$ Shock $)$ & $(200-\alpha)+(1-\beta) \times($ Agent production $)$ \\
Treatment & & \\
\hline
\end{tabular}

${ }^{3}$ It follows that the principal may not be able to sell the company ( $\beta=100 \%$ ) to an agent who is perceived to be risk seeking.

${ }^{4}$ Agents' earnings were not allowed to be negative. However, this limited liability almost never applied in practice since in all cases but four (96\% of the observations) did the agent produce more than 1004 .

${ }^{5}$ Alternatively, one could test the risk-neutrality assumption by designing an experiment in which the principal is engaged in multiple agency relationships for which the Shock $(x)$ on agents' production is independently distributed across agents. 
We must acknowledge that the baseline treatment is not free from risk considerations. The relationship between the agent's effort and the agent's production is not strictly deterministic whenever considering a real work task. For example, the agent may find the solution of a given summation problem by chance. Also, agents may not know their ability on the task with certainty. Given the low complexity of the task, however, we believe that the amount of risk affecting the agent is limited in the baseline compared to the noise treatment. For example, luck is unlikely to be an important factor in the performance of the agent on the summation task. Also, agents are likely to be accurate in assessing their summation skills. ${ }^{6}$

In this paper, we are interested in assessing the tradeoff between risk and incentives. To that end, we only needed to create an environment (the noise treatment) which was riskier for the agent than the baseline environment. Our main question is to assess whether risk-neutral principals effectively insulate agents from the additional amount of risk they face in the noise treatment. Doing so would lead principals to offer a higher fixed pay but a lower share of production in the noise treatment than in the baseline.

\subsection{Procedures}

Our subject pool consisted of students from a major U.S University. We conducted a total of ten sessions with ten or twelve subjects each for a total of 106 subjects. Subjects were randomly assigned to treatments (54 in the baseline and 52 in the noise treatment). ${ }^{7}$

The experiment was computerized and all of the interaction was anonymous. The instructions were displayed on subjects' computer screens. Subjects had exactly 20 minutes to read the instructions. A 20-minute timer was shown on the laboratory screen. Three minutes before the end of the instructions period, a monitor announced the time remaining and handed out a printed copy of the summary of the instructions.

Subjects' risk attitudes and social preferences were elicited at the end of each experimental session. We elicited risk attitudes following Holt and Laury (2002) by asking subjects to make ten binary lottery choices. One lottery (out of 10) was selected at random for each player and used for payments. We also elicited subjects' beliefs about others' risk attitudes. To that end, we asked them to guess the ten lottery choices of another subject selected at random in the same experimental session. We used their guesses in this task to approximate their beliefs about

\footnotetext{
${ }^{6}$ Adding is a widely used skill which is evaluated at school and in standard tests granting access to university.

${ }^{7}$ Out of the ten sessions, seven were conducted with ten people and three were conducted with twelve.
} 
others' risk attitudes. Two subjects were picked at random in each session for payments. The predictions of the first subject were used to forecast the second subject's lottery choices. The guesser was paid \$1.00 for each correct answer (see Appendix D.1). We also elicited social preferences à la Bartling et al. (2009) by asking subjects to make four choices between two possible allocations of money between themselves and another anonymous subject with whom they were randomly matched in the same experimental session (see Appendix D.2). Finally, we collected a self-reported measure of math skills by asking subjects to rate their math skills using a 7-point scale from poor to excellent.

Subjects were paid their earnings in cash. Individual earnings at the end of the experiment were computed as the sum of the earnings in the 6 periods and their earnings in the beliefs elicitation tasks. Subjects earned on average \$25.3 completing the one-hour task in addition to a \$7.00 show-up fee. The hourly payment for the task was three times larger than the minimum wage in the state where the experiment took place. Experimental sessions lasted on average two hours.

\section{RESULTS}

We start the results section by comparing principals' offers across treatments. We then study contract acceptance, effort and production levels. In our analysis, we use linear and probit panel regressions with random effects and robust standard errors. This leaves us with a total of 324 (54×6 periods) observations for the baseline and $312(52 \times 6)$ observations for the noise treatment.

\subsection{Principals' contract offers}

In this section we consider all principals' offers regardless of whether they were accepted or not by the agent.

\subsubsection{Contract offers across treatments}

In line with Hypothesis 1a, we find that principals offered on average a higher fixed pay and a lower share of production in the noise treatment $(95.7 \$$ and $38.7 \%)$ than in the baseline $(90.3 \leftarrow$ and $42.5 \%$ ). Treatment differences in the fixed pay and in the share of production are significant (see last column in Table 2). 
TABLE 2. Principals' offers across treatments.

\begin{tabular}{ccc|c}
\hline $\begin{array}{c}\text { Average } \\
\text { (Standard dev.) }\end{array}$ & Baseline & $\begin{array}{c}\text { Noise } \\
\text { Treatment }\end{array}$ & $\begin{array}{c}\text { Noise Treatment } \\
\text { Dummy } \\
\text { P-value }\end{array}$ \\
\hline Fixed pay & $\begin{array}{c}90.3 థ \\
(34.9 థ)\end{array}$ & $\begin{array}{c}95.7 \Phi \\
(33.3 థ)\end{array}$ & 0.040 \\
Production Share & $\begin{array}{c}42.5 \% \\
(16.9 \%)\end{array}$ & $\begin{array}{c}38.7 \% \\
(13.0 \%)\end{array}$ & 0.020 \\
\hline
\end{tabular}

The p-value in the last column refers to linear panel regressions with random effects and robust standard errors, with fixed pay (top cell) and production share (bottom cell) as dependent variables, and the Noise Treatment Dummy as independent variable. The Noise Treatment Dummy takes value 1 if a subject was involved in the noise treatment and value 0 otherwise.

In line with theory, we also report a negative and significant Spearman correlation coefficient between fixed pay and production share in both the baseline $(-0.22$, $p$-value $=0.013)$ and the noise treatment $(-0.42$, p-value $<0.001)$.

\subsubsection{Contract offers and risk attitudes in the noise treatment}

We investigate Hypothesis 1b by assessing the link between principals' beliefs about others' risk attitudes and their offers in the noise treatment. We follow Holt and Laury (2002) and consider the number of safe choices in the ten binary lottery choices to categorize subjects' own risk attitudes and subjects’ beliefs about the risk attitudes of others (see Table 3). ${ }^{8}$

TABLE 3. Subjects' risk attitudes and beliefs about others' risk attitudes.

\begin{tabular}{cccc}
\hline \hline & Own risk attitudes & & $\begin{array}{c}\text { Beliefs about others' risk attitudes } \\
\text { Subjects (proportion) }\end{array}$ \\
\cline { 1 - 2 } Risk averse & $25(54.4 \%)[66.0 \%]$ & $22(47.8 \%)$ \\
Risk neutral & $18(39.1 \%)[26.0 \%]$ & $21(45.7 \%)$ \\
Risk seeking & $3(6.5 \%)[8.0 \%]$ & & $4(6.5 \%)$ \\
\hline
\end{tabular}

The distribution of subjects in each "own risk attitudes” category does not significantly differ from the results reported in Holt and Laury (2002) (Pearson $\chi^{2}$ test, p-value $\left.=0.260\right)$. In line with previous research, we report widespread risk aversion in our sample. Additionally, although subjects seem to perceive others as slightly less risk averse than themselves, we report no differences between the distribution of “own risk attitudes” and the "beliefs about others' risk attitudes” (Pearson $\chi^{2}$ test, $\mathrm{p}$-value $\left.=0.697\right)$.

\footnotetext{
${ }^{8}$ We report data for the subjects who completed the ten binary lottery choices without switching back and forth between the safer and the riskier options. The proportion of inconsistent switching was almost the same for own risk attitudes, $11.5 \%$ (6/52), and beliefs about others' risk attitudes, 9.6\% (5/52), and it was similar to the proportion reported in Holt and Laury (2002) (about 10\% of the cases).
} 
In line with Hypothesis 1b, we expect principals who perceive others as more risk averse to provide additional insurance to agents by offering them a higher fixed pay and a lower share. We support this conjecture in Table 4 where we report average fixed pay and share of production according to principals’ beliefs about others’ risk attitudes.

TABLE 4. Principals’ average offers across beliefs about others’ risk attitudes (noise treatment).

\begin{tabular}{|c|c|c|c|c|}
\hline \multirow{2}{*}{$\begin{array}{c}\text { Average } \\
\text { (Std. Dev.) }\end{array}$} & \multicolumn{2}{|c|}{ All Periods } & \multicolumn{2}{|c|}{ First Contract Only } \\
\hline & Fixed pay & Share & Fixed pay & Share \\
\hline \multicolumn{5}{|c|}{ Beliefs about others } \\
\hline Risk averse & $\begin{array}{l}102.2 \Phi \\
(26.2 \Phi)\end{array}$ & $\begin{array}{r}37.4 \% \\
(11.1 \%)\end{array}$ & $\begin{array}{l}107.1 \Phi \\
(23.3 థ)\end{array}$ & $\begin{array}{r}35.8 \% \\
(10.7 \%)\end{array}$ \\
\hline \multirow[t]{2}{*}{ Risk neutral } & 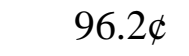 & $39.1 \%$ & 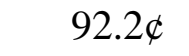 & $38.3 \%$ \\
\hline & $(38.7 \Phi)$ & $(10.8 \%)$ & $(31.64)$ & $(11.9 \%)$ \\
\hline \multirow[t]{2}{*}{ Risk seeking } & 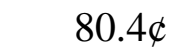 & $42.3 \%$ & 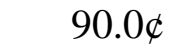 & $41.7 \%$ \\
\hline & $(26.0 థ)$ & $(19.1 \%)$ & $(17.34)$ & $(7.6 \%)$ \\
\hline
\end{tabular}

In the noise treatment, subjects' beliefs about others' risk attitudes may have been affected by agents' decisions to accept or reject offers. This endogeneity issue regarding beliefs about others' risk attitudes may have affected the results reported in Table 4 (All Periods columns). However, we obtain similar results when restricting our analysis to the first contract offered by a subject in which case the contract offer could not have been affected by prior agents' decisions (see last two columns in Table 4).

Our regression analysis confirms that principals offer higher fixed pay and lower shares when they perceived others to be risk averse than when they did not (see Table B1 in the appendix). However, the effect is only marginally significant for fixed pay (p-value [one tailed] $=0.145$ [0.072] for all periods and p-value [one tailed] $=0.072[0.036]$ for the first contract only) while not being statistically significant for shares of production (p-value [one tailed] $=0.318$ [0.159] for all periods and p-value [one tailed] $=0.366$ [0.183] for the first contract only). ${ }^{9}$

In line with Hypothesis 1b, we show that the comparison of contract offers between the noise treatment and the baseline crucially hinges upon principals' beliefs regarding agents' risk attitudes. For example, principals' offers do not differ across treatments when considering only the case of principals who believe others are risk neutral (see last two columns in Table 5). In the

\footnotetext{
${ }^{9}$ Not surprisingly, the coefficient of Others' Risk Aversion is not significant in explaining either the fixed pay or the share of production when conducting the same analysis for the baseline treatment (where no noise is introduced in the agent's payoff function) (p-values $>0.250$ ).
} 
case in which principals believe agents are risk averse they offer significantly higher fixed pay and lower shares of production than in the baseline (see first two columns Table 5). ${ }^{10}$

TABLE 5. Linear panel regressions for principals' fixed pay and share offers in the noise treatment compared to the baseline across beliefs about others' risk attitudes.

\begin{tabular}{ccccc}
\hline \hline & \multicolumn{2}{c}{ Principals' beliefs about others’ risk attitudes } \\
& \multicolumn{2}{c}{ Risk averse } & \multicolumn{2}{c}{ Risk neutral } \\
\hline \hline Dependent variables & Fixed pay & Share & Fixed pay & Share \\
\hline \multirow{2}{*}{ Constant } & 54.973 & $96.278^{* * *}$ & 43.652 & $61.537^{* * *}$ \\
& $(63.332)$ & $(25.673)$ & $(63.332)$ & $(1.867)$ \\
\multirow{2}{*}{ Noise Treatment Dummy } & $6.491^{* *}$ & $-2.413^{* *}$ & 2.272 & -.450 \\
& $(2.770)$ & $(1.107)$ & $(2.864)$ & $(1.153)$ \\
\hline $\mathrm{N}$ & 129 & 129 & 136 & 136 \\
$\mathrm{R}^{2}$ & 0.032 & 0.020 & 0.004 & 0.001 \\
Prob $>\chi^{2}$ & 0.019 & 0.029 & 0.428 & 0.693 \\
\hline
\end{tabular}

\subsection{Contracts' acceptance}

The majority of offers were accepted by agents in both the baseline (75.9\%, 123/162) and the noise treatment (80.1\%, 125/156). We find no difference in acceptance rates across treatments (see Table B2 in the appendix). In our regression analysis, we use as dependent variable a dummy (Accepted dummy) that takes value 1 if a given offer is accepted and takes value 0 otherwise. Not surprisingly, agents are more likely to accept the principal's offer when the fixed pay or the share of production assigned to the agent increase. However, the treatment dummy is never significant at standard levels.

\subsection{Effort and production: The shocking effect of random shocks}

According to Hypothesis 2, we expect effort and production levels to be higher in the baseline treatment in which incentives, as we have confirmed, are stronger than in the noise treatment. In sharp contrast with this conjecture, we observe that effort and production levels are significantly higher in the noise treatment than in the baseline. In the noise treatment, agents produce on average 19.8\% more (\$3.88 per 10-minute period) than in the baseline (\$3.24) despite receiving significantly lower shares of production (see Figure 2). This corresponds to a difference in subjects’ hourly production of \$4.68 (6×[3.88-3.24]).

\footnotetext{
${ }^{10}$ We did not estimate the regression for the case of risk seeking beliefs because of insufficient observations.
} 


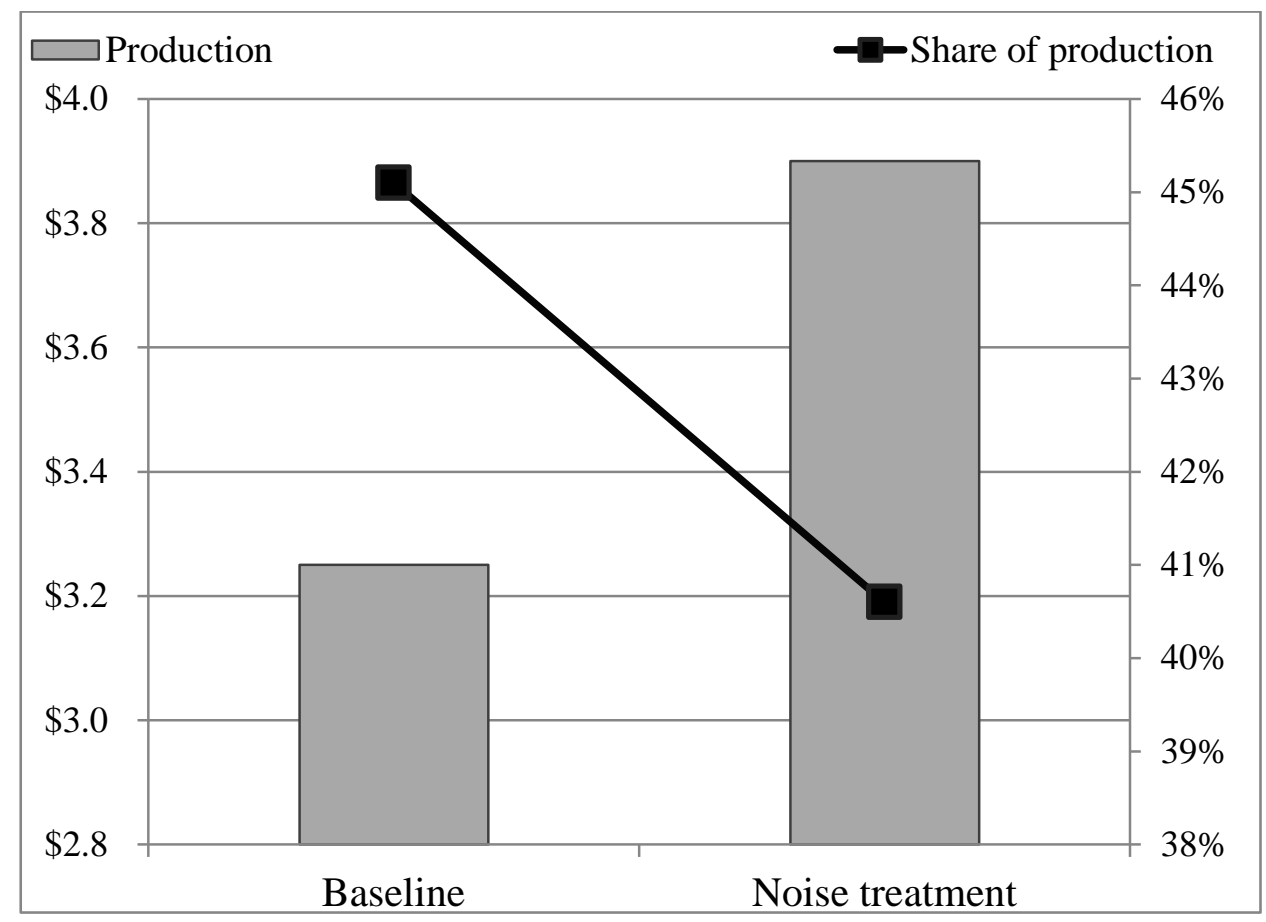

FIGURE 2.- Agents' average production per period (in \$) and share of production (for accepted offers) across treatments. Production is defined as the monetary amount in US dollars generated by the agent in a 10-minute period.

We confirm the statistical significance of these differences in Table $6 .{ }^{11}$ In our analysis, we control for subjects' ability on the task. First, we define a dummy variable which takes value 1 if a subject has completed his or her first table correctly and value 0 otherwise. Previous research has shown the positive relationship between first table performance and ability on the task (Corgnet, Gómez-Miñambres and Hernan-Gonzalez, 2014; Corgnet, Hernan-Gonzalez and Rassenti, 2014). Second, we use subjects' self-reported math skills. The Noise Treatment Dummy is significant and positive across all specifications, indicating higher levels of production in the noise treatment compared to the baseline.

\footnotetext{
${ }^{11}$ We do not include fixed pay and production share as independent variables in the same regression so as to avoid collinearity issues. However, our findings are robust to introducing both variables (or none) in the same regression.
} 
TABLE 6. Linear panel regressions for agent production.

\begin{tabular}{|c|c|c|c|c|c|c|}
\hline \multirow{2}{*}{$\begin{array}{c}\text { Dependent Variable } \\
\text { Constant }\end{array}$} & \multicolumn{6}{|c|}{ Agent production } \\
\hline & $\begin{array}{c}2.518 * * * \\
(0.400)\end{array}$ & $\begin{array}{c}1.978 * * * \\
(0.428)\end{array}$ & $\begin{array}{c}0.718 \\
(0.698)\end{array}$ & $\begin{array}{c}3.442 * * * \\
(0.359)\end{array}$ & $\begin{array}{c}2.906 * * * \\
(0.389)\end{array}$ & $\begin{array}{c}1.796 * * \\
(0.759)\end{array}$ \\
\hline Noise Treatment Dummy & $\begin{array}{c}0.737 * * \\
(0.315)\end{array}$ & $\begin{array}{c}0.727 * * \\
(0.304)\end{array}$ & $\begin{array}{l}0.572 * \\
(0.309)\end{array}$ & $\begin{array}{c}0.703^{* *} \\
(0.315)\end{array}$ & $\begin{array}{c}0.691 * * \\
(0.304)\end{array}$ & $\begin{array}{l}0.545^{*} \\
(0.309)\end{array}$ \\
\hline \multicolumn{7}{|l|}{$\underline{\text { Contract offer }}$} \\
\hline Fixed pay & - & - & - & $\begin{array}{l}-0.004 \\
(0.003)\end{array}$ & $\begin{array}{l}-0.004 \\
(0.003)\end{array}$ & $\begin{array}{l}-0.004 \\
(0.003)\end{array}$ \\
\hline Production share & $\begin{array}{l}0.012^{*} \\
(0.007)\end{array}$ & $\begin{array}{l}0.013 * \\
(0.007)\end{array}$ & $\begin{array}{l}0.013^{*} \\
(0.007)\end{array}$ & - & - & - \\
\hline \multicolumn{7}{|l|}{$\underline{\text { Ability measures }}$} \\
\hline First table correct & - & $\begin{array}{c}0.651^{* * *} \\
(0.169)\end{array}$ & - & - & $\begin{array}{c}0.634 * * * \\
(0.175)\end{array}$ & - \\
\hline Self-reported skills & - & - & $\begin{array}{c}0.359 * * * \\
(0.124)\end{array}$ & - & - & $\begin{array}{c}0.336 * * * \\
(0.126)\end{array}$ \\
\hline $\begin{array}{c}\mathrm{N} \\
\mathrm{R}^{2} \\
\text { Prob }>\chi^{2}\end{array}$ & $\begin{array}{c}239 \\
0.040 \\
0.023\end{array}$ & $\begin{array}{c}239 \\
0.104 \\
<0.001\end{array}$ & $\begin{array}{c}239 \\
0.101 \\
0.001\end{array}$ & $\begin{array}{c}239 \\
0.034 \\
0.048\end{array}$ & $\begin{array}{c}239 \\
0.096 \\
<0.001\end{array}$ & $\begin{array}{c}239 \\
0.089 \\
<0.001\end{array}$ \\
\hline
\end{tabular}

In addition, agents exert more effort in the noise treatment than in the baseline. We assessed effort by studying the number of tables agents completed as well as the time spent working instead of browsing the web (see Table 7 and Table B3 in the appendix for the statistical analysis). ${ }^{12}$ In the noise treatment agents completed $17.7 \%$ more tables than in the baseline and spend substantially less time browsing the web (7.8\%) than in the baseline (13.9\%). These differences are statistically significant (see Table B3, p-values < 0.05). The increase in production in the noise treatment compared to the baseline is explained both by a decrease in internet browsing and by an increase in productivity, measured as the agent's production per minute spent on the task screen.

\footnotetext{
${ }^{12}$ Given the results in Table 7 we use share of production rather than fixed pay as a control for the strength of incentives. Our results are robust to controlling for fixed pay instead.
} 
TABLE 7. Effort and productivity across treatments. Average (standard deviation)

\begin{tabular}{cll}
\hline \hline & Baseline & Noise treatment \\
\hline Time on the task (\%) & $86.13 \%(25.59 \%)$ & $92.24 \%(16.89 \%)$ \\
Completed tables & $9.76(4.80)$ & $11.48(3.99)$ \\
Productivity per minute & $\$ 0.36(\$ 0.16)$ & $\$ 0.42(\$ 0.15)$ \\
\hline
\end{tabular}

Given the higher level of production in the noise treatment than in the baseline, it is not surprising that principals' earnings were significantly higher in the presence of noise (see last two columns in Table B3). The average hourly earnings for principals were equal to $\$ 19.7$ in the noise treatment compared to $\$ 16.8$ in the baseline. This result contrasts with the prediction of the standard principal-agent model. According to this model, principals should earn less in the noisy environment than in the baseline as they need to ensure agents against risk by paying them higher wages. We find the exact opposite. So, why are agents more productive and principals better off in the noise treatment than in the baseline despite weaker incentives?

\section{THE SHOCKING EFFECT OF RANDOM SHOCKS: POSSIBLE EXPLANATIONS}

\subsection{Risk attitudes}

One may attempt to explain the positive effect of noise on effort, production and principals' earnings by referring to atypical risk attitudes. However, as we showed in Section 4.1, our subjects' risk attitudes closely mimic the original results reported in Holt and Laury (2002) showing that the majority of subjects are risk averse. We also showed that principals purposefully adjust offers to their perception of others' risk attitudes. Note that in the extreme case in which principals perceive agents as risk seeking, they should offer agents higher shares of production in the noise treatment than in the baseline which is in contradiction with our empirical results. One remaining possibility is that risk-averse agents as measured using binary lottery choices à la Holt and Laury (2002) are risk seeking when deciding to undertake a realeffort task with noise. For this explanation to be consistent with lower shares offered to agents in the noise treatment than in the baseline, it would still have to be the case that principals misperceive agents as being risk averse when undertaking the real-effort task. This misperception of agents' risk attitudes is unlikely in our experimental design given that principals also played the role of agents. 
Nonetheless, we conducted an additional treatment recruiting a total of 60 subjects to inquire on risk attitudes in our real-effort task environment (see Appendix D.3 for details). Using a strategy-method approach, we asked subjects, for a given share of production, the minimum fixed pay they would be willing to accept for working on the 10-minute summation task instead of receiving an outside payment of $150 \notin$ to browse the Internet. We asked subjects to consider both a certain and a random scenario in which their earnings were computed as for the agents in our baseline and noise treatments, respectively. The two scenarios were presented in random order. We classify a majority of subjects (65\%) as risk averse as they demanded, on average, a greater fixed pay to accept completing the work task in the noise treatment (118.5 $\$$ ) than in the baseline (109.9 $).^{13}$ These findings help us to discard the fact that agents may have been risk seeking in the context of our real-effort experimental environment. ${ }^{14}$

We now consider two seminal behavioral theories which have been widely used to account for a number of apparent anomalies: social preferences (see e.g. Fehr and Schmidt, 1999; Charness and Rabin, 2002) and loss aversion (see e.g. Kahneman and Tversky, 1979; Tversky and Kahneman, 1992).

\subsection{Social preferences}

Previous research has shown the importance of other-regarding preferences to explain subjects’ behaviors in a wide range of experiments including dictator, ultimatum, public good and giftexchange games (Fehr and Schmidt, 1999; Bolton and Ockenfels, 2000; Charness and Rabin, 2002). Keser and Willinger (2003; 2007) have also stressed the importance of fairness concerns in principal-agent situations. Anderhub, Gächter and Königstein (2010) show that considerations for contractual fairness and reciprocity affect principals and agents behaviors in a principal-agent experiment with chosen effort and without noise. The authors find that the most popular contract (30\% of the cases) offers an equal split of the surplus between the agent and the principal. In our case, the most common offer (16.7\% of the cases) was a $50 \%$ share of production with a wage of

\footnotetext{
${ }^{13}$ For a more precise classification of risk attitudes that allows for risk neutrality, we can consider subjects as risk neutral if the average fixed pay they demanded in the noise treatment was within $10 \%$ of the average fixed pay demanded in the baseline. Using this criterion, $47.3 \%$ (30.9\%) [21.8\%] of the subjects were classified as risk averse (risk neutral) (risk seeking). This empirical distribution of risk attitudes does not significantly differ from the empirical distribution established using the Holt and Laury (2002) lottery techniques (see Table 4) $\left(\chi^{2}\right.$ test, p-value $=$ $0.62)$.

${ }^{14}$ The design of this study was aimed at eliciting risk attitudes in the real-effort task and not at studying production. The risk-elicitation study differed in a number of important dimensions (e.g. random versus human contract offers) from the original study making the study of production across scenarios uninformative (see Appendix D.3 for details).
} 
$100{ }^{15}$ This offer is the only one that ensures equal (expected) earnings for both the agent and the principal in the baseline (noise treatment).

To investigate the role of social preferences in our setting, we introduce other-regarding preferences in the LEN principal-agent model presented in Section 2 following Rotemberg (1994) and Charness and Rabin (2002). ${ }^{16}$ In both models, the authors capture distributive preferences by the weight $(w)$ each person assigns to the other person's monetary payoffs (certainty equivalents in our case) in his or her utility function. In our case, this implies that the principal will maximize the following function: $\left(1-w_{P}\right)[\theta \mathrm{e}-y]+w_{P}[\alpha+\beta e-C(e)-$ $\left.\frac{1}{2} r \beta^{2} \sigma^{2}\right]$ whereas the agent's certainty equivalent becomes: $\left(1-w_{A}\right)[\alpha+\beta e-C(e)-$ $\left.\frac{1}{2} r \beta^{2} \sigma^{2}\right]+w_{A}[\theta \mathrm{e}-y]$, where $w_{P}\left(w_{A}\right)$ in $\left.] 0, \frac{1}{2}\right]$ is the weight the principal (the agent) assigns to the agent's (principal's) certainty equivalent. We solve this extended version of the LEN principal-agent model similarly to the standard model (see Appendix A) and show that the tradeoff between risk and incentives continue to operate in the presence of social preferences. We summarize our conjectures below.

\section{Proposition 1 (Principal-agent model with social preferences)}

In the presence of social preferences, principals offer lower shares and higher wages to agents in the presence of noise than in its absence. Agents exert less effort and produce less in the presence of noise.

Proposition 1 shows that the main implications of the principal-agent model are robust to introducing social preferences. Social preferences affect, however, the magnitude of the tradeoff between risk and incentives. For example, if agents assign a large weight to the principal's payoffs the tradeoff between risk and incentives will be milder. This implies that the principal will select incentives levels $(\beta)$ in the noise treatment that are almost as high as in the baseline while paying a fixed pay $(\alpha)$ that is only slightly higher. However, accounting for social preferences does not help explain why agents exert more effort in the noise treatment than in the baseline despite receiving weaker incentives to produce.

\footnotetext{
15 The proportion of this type of offers was $20.3 \%$ (12.8\%) in the baseline (noise treatment). The difference of proportions across treatment was only marginally significant $(\mathrm{p}$-value $=0.073)$.

${ }^{16}$ Alternatively, one could include inequity aversion à la Fehr and Schmidt (1999) in the LEN principal-agent model following the steps of Englmaier and Wambach (2010).
} 
In our social preferences model, we have not introduced reciprocal concerns as is the case, for example, in Charness and Rabin (2002). It may be argued that agents respond favorably to principals’ offers in the noise treatment because they provide generous insurance to the former. In contrast with the gift-exchange argument, however, fixed pay does not affect agents' production levels in our setting as is shown in Table 6. Also, accepted offers in the noise treatment are actually less generous than in the baseline. The fixed pay for accepted offers is only $3.7 \nsubseteq$ higher on average in the noise treatment than in the baseline and this difference is not significant (p-value $=0.341$ ). ${ }^{17}$ The modest increase in the fixed pay for accepted offers in the noise treatment is more than offset by the lower share of production in the noise treatment (40.6\%) than in the baseline (45.1\%). ${ }^{18}$ The decrease in share of production implies, considering the average level of production in the baseline treatment (3884), an average decrease in agents' earnings of $17.5 \mathbb{}$ in the noise treatment compared to the baseline. Not surprisingly the share of total earnings obtained by the agent was lower in the noise treatment (44.9\%) than in the baseline (47.1\%). ${ }^{19}$

In order to further assess the impact of social preferences, we replicate the regression analyses presented in Section 4 controlling for social preferences. We use as a measure of social preferences the test introduced in Bartling et al. (2009). Following Bartling et al. (2009), we classify subjects as either ahead averse, behind averse or egalitarian creating dummy variables for each type of social preferences (see Appendix D.2). All our findings are shown to be robust to these additional controls (see Appendix C). In most of the cases, social preferences dummies are not statistically significant. One exception is the fact that egalitarian or ahead-averse principals tend to offer a higher fixed pay to agents. Ahead-averse principals also offer higher shares of production to agents (see Table C1).

\subsection{Shocking or not shocking: The role of loss aversion}

We now turn to loss aversion as a possible explanation for the fact that agents produce significantly more in the noise treatment than in the baseline despite weaker incentives. Numerous studies have shown that behavior is affected by reference points (see Kahneman and Tversky, 2000 for a review). More precisely, evidence from psychology (Heath, Larrick, and $\mathrm{Wu}, 1999)$ suggests that the marginal utility of a dollar is strictly higher below the reference

\footnotetext{
${ }^{17}$ We report the p-value for the noise treatment coefficient using the same regression as in Table 2 restricting our analysis to accepted offers.

${ }^{18}$ Note that the difference in shares of production (for accepted offers) is significant (p-value $=0.008$ ).

${ }^{19}$ This difference is marginally significant ( $\mathrm{p}$-value $=0.083$ for the noise treatment coefficient).
} 
point than above. This implies that people will behave differently whether their currents earnings are below or above their reference earnings. Relatedly, Fehr and Goette (2007) found that lossaverse bike messengers reduced their effort as a result of a wage increase as they were able to surpass their daily income target with less effort. Relatedly, the fact that loss aversion may lead to an increase in production has been noted by Sloof and van Praag (2010) in a real-effort experiment in which agents work under a pre-specified incentive contract (i.e. an incentive contract specified by the experimenter). More recently, field works have shown that using a loss frame rather than a gain frame led people to exert higher effort (Fryer et al. 2012; Hossain and List, 2012).

We assess whether loss aversion can account for our experimental findings by developing a standard principal-agent model with loss averse agents. We consider a piecewise linear specification of the value function to isolate the effect of loss aversion from risk attitudes (see e.g. Fehr and Goette, 2007). The principal is assumed to be risk neutral as in the standard principal-agent model while the agent is assumed to be loss averse. We consider a random shock that takes value $x$ or $-x$ with equal probability so that the output of effort observed by the principal ( $z$ ) is either $z=e-x$ or $z=e+x$. We consider that the agent is in the loss domain if the random shock is negative and is in the gain domain, otherwise. We are thus assuming that the earnings of the agents are systematically below their reference level $(R)$ whenever the random shock is negative and above their reference level whenever the random shock is positive. To account for our experimental results, we only need to assume that a positive proportion of the subjects satisfy this assumption. We may still have a number of subjects who do not respond to random shocks because they have particularly low or particularly high reference earnings.

In our model, the principal maximizes expected payoffs $(\theta \mathrm{e}-y)$ while the agent maximizes the following function: $\frac{1}{2} \lambda[\alpha+\beta(e-x)-R]+\frac{1}{2}[\alpha+\beta(e+x)-R]-C(e)$, where $\lambda>1$ is the degree of loss aversion. We consider the following specification: $C(e)=\varphi e^{2}$. The principalagent problem is solved as follows.

$$
\begin{aligned}
& \operatorname{Max}_{\alpha, \beta} \theta \mathrm{e}-(\alpha+\beta e) \\
& \text { s.t } \beta=\frac{4 \varphi e}{\lambda+1}(I C) \\
& \text { s.t } \frac{1}{2} \lambda[\alpha+\beta(e-x)-R]+\frac{1}{2}[\alpha+\beta(e+x)-R]-\varphi e^{2} \geq v_{0}
\end{aligned}
$$


Solving this maximization problem, we obtain that $\beta^{*}=\theta-4 \varphi \frac{\lambda-1}{(\lambda+1)^{2}} x$ and $e^{*}=\frac{\lambda+1}{4 \varphi} \theta-$ $\frac{\lambda-1}{\lambda+1} x$. We observe that loss aversion similarly to risk aversion leads to a decrease in the strength of incentives $(\beta)$ in the presence of noise $(x>0)$ compared to the case in which there is no noise $\left(\beta^{*}=\theta\right.$ if $\left.x=0\right)$. Under loss aversion, an increase in $\beta$ incentivizes the agent as it increases the weight of pay-for-performance, but, it also increases the magnitude of potential losses incurred in the presence of the negative shock $(-x)$. The optimal contract is for the principal to select an intermediate value of $\beta$ that incentivizes the agent to produce while not inducing an unbearable amount of potential losses. As a result, the tradeoff between risk and incentives identified in the standard model is replaced by a similar tradeoff between potential losses and incentives. However, the loss-aversion model differs from the one with risk aversion as weaker incentives need not entail a decrease in production in the presence of noise. In the absence of noise $(x=0)$, the optimal level of effort is such that $e^{*}{ }_{x=0}=\frac{\theta}{2 \varphi}$ if $\alpha^{*}{ }_{x=0}+$ $\beta_{x=0}^{*} e_{x=0}^{*} \geq R$ and $e_{x=0}^{*}=\frac{\lambda \theta}{2 \varphi} \quad$ otherwise. It follows that, as long as the agent is not systematically in the loss domain in the absence of noise $\left(\alpha^{*}{ }_{x=0}+\beta_{x=0}^{*} e_{x=0}^{*} \geq R\right)$, the optimal level of effort is higher in the presence of noise than in its absence if loss aversion is sufficiently large. ${ }^{20}$ Indeed, we have that: $e^{*}>e^{*}{ }_{x=0} \Leftrightarrow \frac{\lambda+1}{4 \varphi} \theta-\frac{\lambda-1}{\lambda+1} x>\frac{\theta}{2 \varphi} \Leftrightarrow \lambda>\frac{4 \varphi}{\theta} x-1$. In that case, noise leads to higher levels of effort $\left(e^{*}>e^{*}{ }_{x=0}\right)$ despite leading the principal to set weaker incentives $\left(\beta^{*}<\beta_{x=0}^{*}\right)$. This follows from the fact that negative shocks force the agent into the loss domain where, as is assumed in reference-dependent models, the marginal product of effort is higher than in the gain domain.

We summarize our findings as follows.

\section{Proposition 2 (Principal-agent model with loss aversion)}

In the case of loss averse agents, principals offer lower shares of production and higher wages in the presence of noise than in its absence. Loss averse agents may exert more effort and produce significantly more in the presence of noise for sufficiently high levels of loss aversion.

Proposition 2 is consistent with the fact that agents exert more effort in the noise treatment than in the baseline despite principals offering lesser pay for performance. The fact that an increase in

\footnotetext{
${ }^{20}$ The condition that the agent is not systematically in the loss domain in the absence of noise is automatically satisfied if, for example, we assume that the reference point is equal to the agent's earnings in the absence of noise $\left(R=\alpha_{x=0}^{*}+\beta_{x=0}^{*} e_{x=0}^{*}\right)$.
} 
the level of noise may be beneficial to the principal echoes a growing body of research studying the positive implications of contractual opacity on work performance (e.g. Bernheim and Whinston, 1998; Ederer, Holden and Mayers, 2014; Jehiel, 2014). These works do not incorporate loss aversion, however. Instead, they reflect on the structure and on the partition of information that render opaque contracts optimal. ${ }^{21}$

To obtain direct evidence of the effect of loss aversion in the principal-agent model, we recruited back the subjects who participated in the noise treatment one month after completing the original study. We offered a $\$ 13$ show-up fee to complete a loss-aversion test. Forty out of the fifty two subjects who participated in the original noise treatment came back for the test. ${ }^{22}$ Subjects were asked to complete a loss aversion test which was derived from Gächter, Johnson and Herrmann (2010) and Fehr, Goette and Lienhard (2013). Subjects have to accept or reject each of six lotteries involving losses. Depending on the lottery, subjects can lose up to \$6 which would be subtracted from their \$13 show-up fee (see Appendix D.4). Subjects are characterized as loss averse as long as they reject the last two lotteries. ${ }^{23}$ We find that a majority of subjects (34 over 40) are loss averse in line with our theoretical conjecture and consistently with the data reported by Gächter, Johnson and Herrmann (2010). The median estimate of loss-aversion $(\lambda=1.5)$ coincides with the value reported in Gächter, Johnson and Herrmann (2010) when using a piecewise linear loss function as is assumed in our theoretical model. We study the effect of loss aversion in a regression analysis by creating a dummy variable capturing the history of shocks (Loss Domain Dummy). This variable takes value 1 if a subject has incurred more negative than positive shocks as an agent and value 0 otherwise. We are assuming that subjects perceive that they are in the loss domain whenever they have experienced more negative than positive shocks. We show in Table 8 that agents' produce significantly more when they are in the loss domain (10.9) than when they are not (9.2). We study the relationship between agents' production for different samples of subjects and for different histories of shocks. We consider the samples of loss-averse (column 3) and not-loss-averse subjects (column 4), separately.

\footnotetext{
${ }^{21}$ Bernheim and Whinston (1998) argue that when some aspects of work performance are not verifiable it may be optimal to leave verifiable aspects of performance unspecified. Jehiel (2014) shows that non-transparent contracts are optimal in principal-agent models with moral hazard whenever the principal's information has more dimensions than the action of the agent. Ederer, Holden and Mayers (2014) show that when the agent has more information than the principal, leaving aspects of the contracts unspecified may be optimal for the principal.

${ }^{22}$ We find no differences in average production levels for those subjects who came back (9.5) and those who did not (10.1). We use a panel regression with random effects and robust standard errors with a participation dummy (taking value 1 if a subject came back for the loss aversion test and value 0 otherwise) as independent variable. The p-value for the participation dummy is equal to 0.397 .

${ }^{23}$ No subjects exhibited an inconsistent pattern by switching back and forth between accepting and rejecting the lotteries.
} 
Interestingly, the significant increase in production is limited to loss-averse subjects in line with our model. Even though the sample of subjects who are not loss averse is not large enough to conclude for the absence of an effect of the Loss Domain Dummy in this case, these results suggest that being in the loss domain does not systematically boost agents’ production.

TABLE 8. Linear panel regressions for agent's production as a function of the history of shocks and loss aversion. ${ }^{24}$

\begin{tabular}{cccc}
\hline & All subjects & Loss averse & Not loss averse \\
\hline Constant & $9.066^{* * *}$ & $8.982^{* * *}$ & $9.242^{* * *}$ \\
& $(0.553)$ & $(0.631)$ & $(1.635)$ \\
Loss Domain Dummy & $1.479^{* *}$ & $2.512^{* *}$ & 1.592 \\
& $(0.665)$ & $(1.109)$ & $(1.254)$ \\
\hline $\mathrm{N}$ & 116 & 69 & 12 \\
$\mathrm{R}^{2}$ & 0.034 & 0.079 & 0.210 \\
Prob $>\chi^{2}$ & 0.026 & 0.023 & 0.204 \\
\hline
\end{tabular}

We also show that the noise treatment outperforms the baseline when restricting our analysis to cases in which subjects are in the loss domain (the history of shocks is negative) whereas this is not the case otherwise (see Table B4). In contrast to the theoretical model, our empirical study of loss aversion has focused on the effect of realized losses instead of anticipated losses. This is motivated by the fact that, in our multi-period experimental setting, a subject is affected by the realization of previous shocks. However, the fact that agents produce on average $25.3 \%$ more in the noise treatment (\$3.43) than in the baseline (\$2.73) in their first working period (when no losses had yet been realized) suggests that anticipated losses also matter (see Table B4 in the appendix, last column).

In sum, our empirical analysis provides support for our principal-agent model with loss aversion according to which loss-averse agents will exert more effort in the domain of losses than in the domain of gains.

\footnotetext{
${ }^{24}$ The results of the regressions presented in this table are robust to alternative specifications controlling for production shares, fixed pay as well as subjects' skills.
} 


\section{CONCLUSIONS}

The mixed evidence regarding the tradeoff between risk and incentives in the field instigated our study. Our goal was to assess the relevance of this tradeoff in a controlled environment in which the two experimental treatments only differ in the noisiness of the relationship between effort and output. In line with the standard linear principal-agent model, we found that principals were inclined to hedge agents against risk by offering less risky contracts with higher fixed pay and lesser pay for performance in the noise treatment than in the baseline.

In contrast with the predictions of the principal-agent model, agents exerted more effort and produce more in the noise treatment than in the baseline despite receiving less pay for performance. This implied that principals earned significantly more in the noisy environment. One plausible explanation for this finding relies on agents being loss averse. In this case, the negative incentives effect of weaker pay for performance can be more than offset by the motivational effect of losses. In order to secure the participation of the agent in a noisy environment, the principal hedges the agent against unbearable losses by offering higher fixed pay and lesser pay for performance. Interestingly, the principal is better off in a noisy environment because the loss-averse agent, striving to avoid losses, works harder in the presence of noise. This suggests that in the principal-agent model with loss-averse agents, the principal will maximize payoffs by purposefully selecting the level of noisiness between effort and output $\left(\sigma^{2}\right)$ in addition to choosing fixed pay $(\alpha)$ and pay for performance $(\beta)$. In particular, managers may be interested in designing work environments for which the relationship between agent effort and output is particularly noisy, for example, by purposefully ignoring accurate pieces of information when designing the incentive contract. From both a theoretical and empirical standpoint, a promising avenue for future research would be to evaluate whether the pervasiveness of apparently inefficient managerial practices such as ambiguous feedback,

unclear expectations, office politics or recurrent changes in performance appraisal can be explained by the principal's appeal for noisy work environments.

More generally, our findings call for extending standard agency models by recognizing the motivational role of loss aversion in risky environments. Our results also call for a reassessment of the expectancy theory of motivation in the management literature (Vroom, 1964) recognizing that contractual opacity, by harnessing the motivational power of loss aversion, may lead workers to exert high levels of effort. 


\section{REFERENCES}

Adams, C. (2005): “Agent Discretion, Adverse Selection and the Risk-Incentive Trade-Off,” Working paper, Federal Trade Commission.

Anderhub, V., S. Gächter and M. Königstein (2002): "Efficient Contracting and Fair Play in a Simple Principal-Agent Experiment," Experimental Economics, 5(1), 5-27.

Baker, G., and B. JorgensenV (2003): "Volatility, Noise, and Incentives,” mimeo.

Bartling, B., E. Fehr, M. Marechal, and D. Schunk (2009): "Egalitarianism and Competitiveness,” American Economic Review, 99(2), 93-98.

Bernheim, D. and M. Whinston (1998): "Incomplete Contracts and Strategic Ambiguity," American Economic Review, 88(4), 902-32.

Besanko, D., D. Dranove, S. Schaefter and M. Shanley (2012): “The Economics of Strategy,” $6^{\text {th }}$ edition, John Wiley \& Sons, 2012.

Bolton, P. and M. Dewatripont (2005): Contract Theory. MIT Press, Cambridge, MA.

Bolton, G., A. Ockenfels (2000): A Theory of Equity, Reciprocity, and Competition. American Economic Review, 100, 166-193.

Camerer, C., and R. Weber. (2012). “Experimental Organizational Economics,” R. Gibbons and J. Roberts (eds.), Handbook of Organizational Economics. Princeton, NJ: Princeton University Press, Chapter 6, 213-262.

Charness, G., and P. Kuhn (2011): "Lab Labor: What Can Labor Economists Learn from the Lab?,” in Handbook of Labor Economics, 4, ed. by O. Ashenfelter and D. Card. Elsevier, chapter 03, 229-330.

Charness, G., M. Rabin. (2002): Understanding social preferences with simple tests. Quarterly Journal of Economics 117, 817-869

Corgnet, B., R. Hernan-Gonzalez, S. Rassenti (2014): "Peer Pressure and Moral Hazard in Teams: Experimental Evidence,” Review of Behavioral Economics, In Press.

Corgnet, B., R. Hernan-Gonzalez, S. Rassenti (2013): "Firing Threats and Tenure: Incentive Effects and Impression Management,” Working papers 13-15 Chapman University Economic Science Institute.

Corgnet, B., J. Gómez-Miñambres, R. Hernan-Gonzalez, (2014): “Goal Setting and Monetary Incentives: When Large Stakes Are Not Enough,” Management Science, In Press.

Corgnet B., R. Hernan-Gonzalez, E. Schniter. (2014): "Why Real Leisure Really Matters: Incentive Effects on Real Effort in the Laboratory,” Experimental Economics, In Press.

DeVaro, J., and F. Kurtulus. (2010): “An Empirical Analysis of Risk, Incentives, and the Delegation of Worker Authority” Industrial and Labor Relations Review, 63(4), July 2010, 637-657.

Dohmen, T., and A. Falk. (2011): "Performance Pay and Multi-Dimensional Sorting: Productivity, Preferences and Gender,” American Economic Review, 101(2), 556-590.

Edmans A., and X. Gabaix (2011): "The Effect of Risk on the CEO Market," Review of Financial Studies, 24(8), 2822-2863.

Ederer, F., R. Holden, and M. Meyer (2014): “Gaming and Strategic Opacity in Incentive Provision,” UCLA School of Law, Law-Econ Research Paper No. 13-01. 
Englmaier, F. and A. Wambach (2010): “Optimal Incentive Contracts Under Inequity Aversion,” Games and Economic Behavior, Elsevier, vol. 69(2), pages 312-328, July.

Eriksson, T., A. Poulsen, and M. C. Villeval (2009): "Feedback and Incentives: Experimental Evidence,” Labour Economics, 16 (6), 679-688.

Falk, A. and E. Fehr (2003): "Why Labour Market Experiments?,” Labour Economics, 10(4), 399-406.

Fehr, E. and L. Goette (2007): “Do Workers Work More if Wages are High? Evidence from a Randomized Field Experiment,” American Economic Review, 97, 298-317.

Fehr, E., L. Goette and M. Lienhard (2013): "Loss Aversion and Effort: Evidence from a Field Experiment," mimeo.

Fehr, E., and K. Schmidt (1999): “A Theory of Fairness, Competition, and Cooperation,” Quarterly Journal of Economics, 114(3), 817-868.

Fryer, R., S. Levitt, J. List, and S. Sadoff (2012): "Enhancing the Efficacy of Teacher Incentives Through Loss Aversion: A Field Experiment,” NBER Working Paper 18237.

Gächter, S., E. Johnson and A. Herrmann (2010): "Individual-Level Loss Aversion in Riskless and Risky Choices,” working paper CEDEX, University of Nottingham.

Garen, J. E (1994): “Executive Compensation and Principal-Agent Theory,” Journal of Political Economy, 102(6), 1175-1199.

Gibbons, R. and J. Roberts (2013): "Economic Theories of Incentives in Organizations," Handbook of Organizational Economics, Chapter 2, 56-99.

He, Z., Li, S., Wei, B. and J. Yu (2014): "Uncertainty, Risk, and Incentives: Theory and Evidence,” Management Science, 60(1), 206-226.

Heath, C., R . P. Larrick, and G. Wu (1999): “Goals as Reference Points,” Cognitive Psychology 38, 79-109.

Holmström, B. (1979): “Moral Hazard and Observability,” Bell Journal of Economics, 10(1), 7491.

Holt, C. A., and S. K. Laury. (2002): "Risk Aversion and Incentive Effects,” American Economic Review, 92(5), 1644-1655.

Hossain, T. and J. List. (2012): “The Behavioralist Visits the Factory: Increasing Productivity Using Simple Framing Manipulations,” Management Science, 58(12), 2151-2167.

Jehiel, P. (2014): “On Transparency in Organizations,” Working paper PSE.

Kahneman, D., and A. Tversky (1979): "Prospect Theory: An Analysis of Decisions Under Risk,” Econometrica, 47 (2), 313-327.

Kahneman, D., and A. Tversky (2000): “Choices, Values, and Frames,” Cambridge, New York, and Melbourne: Cambridge University Press.

Keser, C. and M. Willinger (2000): “Principals’ Principles When Agents' Actions are Hidden,” International Journal of Industrial Organization, 18(1), 163-185.

Keser, C. and M. Willinger (2007): "Theories of Behavior in Principal-agent Relationships With Hidden Action,” European Economic Review, 51(6), 1514-1533.

Laffont, J. J., and D. Martimort (2002): The theory of incentives: The principal-agent model. Princeton University Press: Princeton, N.J.; Oxford.

Lazear, E. and P. Oyer (2013): “Personnel Economics,” Handbook of Organizational Economics, Chapter 12, 479-519. 
Milgrom, P., Roberts, J., (1992): Economics, Organization and Management. Prentice Hall.

Niederle, M., and L. Vesterlund (2007): “Do Women Shy Away from Competition? Do Men Compete Too Much?,” The Quarterly Journal of Economics, 3(8), 1067-1101.

Prendergast, C. (2002): “The Tenuous Trade-Off between Risk and Incentives,” The Journal of Political Economy, 110(5), 1071-1102.

Raith, M. (2008): “Specific Knowledge and Performance Measurement," RAND Journal of Economics, 39(4), 1059-1079.

Rotemberg, J. (1994): “Human Relations in the Workplace,” Journal of Political Economy, 102(4), 684-717.

Sloof, R., and C. van Praag (2010): "The Effect of Noise in a Performance Measure on Work Motivation: A Real Effort Laboratory Experiment,” Labour Economics, 17, 751-765.

Smith, V. (1976): “Experimental Economics: Induced Value Theory," American Economic Review, 66(2), 274-279.

Stiglitz, J. (1974): "Incentives and Risk Sharing in Sharecropping," Review of Economic Studies, 41(2), 219-55.

Tversky, A., and D. Kahneman (1992): “Advances in Prospect Theory: Cumulative Representation of Uncertainty,” Journal of Risk and Uncertainty, Springer, 5(4), 297-323.

Vroom, V. (1964): “Work and Motivation,” San Francisco, CA: Jossey-Bass.

Zabojnik, J. (1996): “Pay-performance Sensitivity and Production Uncertainty”. Economics Letters 53(3), 291-296. 


\section{APPENDIX A. The LEN principal-agent model with social preferences}

The principal will maximize the following function subject to the incentive and participation constraints of the agent, where $\mathrm{u} C(e)=\varphi e^{2}$ with $\varphi>0$.

$$
\begin{aligned}
& \operatorname{Max}_{\alpha, \beta}\left(1-w_{P}\right)[\theta \mathrm{e}-y]+w_{P}\left[\alpha+\beta e-C(e)-\frac{1}{2} r \beta^{2} \sigma^{2}\right] \\
& \text { s.t } \beta=\frac{2\left(1-w_{A}\right) \varphi e-w_{A} \theta}{1-2 w_{A}}\left(I C_{s p}\right) \\
& \text { s.t }\left(1-w_{A}\right)\left[\alpha+\beta e-\varphi e^{2}-\frac{1}{2} r \beta^{2} \sigma^{2}\right]+w_{A}[\theta \mathrm{e}-y] \geq v_{0} \quad\left(P C_{s p}\right)
\end{aligned}
$$

That is equivalent to:

$\operatorname{Max}_{e}\left(1-w_{P}\right)[\theta \mathrm{e}-y]+w_{P}\left[\alpha+\beta e-C(e)-\frac{1}{2} r \beta^{2} \sigma^{2}\right]$

First order condition:

$$
\begin{aligned}
& \left(2 \varphi w_{A}^{2}+2 r \sigma^{2}\left(1-w_{A}\right) \varphi\right) e^{*}=2\left(1-w_{A}\right) w_{A} \varphi \theta \\
& \quad+\frac{\left.\left(2\left(1-w_{A}\right)-1\right)^{3}\left(1-w_{P}\right) \theta+\left(2\left(1-w_{A}\right)-1\right)^{2} w_{A}\right)\left(2\left(1-w_{P}\right)-1\right)}{\left(2\left(1-w_{P}\right)-1\right)\left(1-w_{A}\right)+w_{P}}
\end{aligned}
$$

If follows from the first order condition that: $\frac{\partial e^{*}}{\partial \sigma^{2}}<0$ and $\frac{\partial e^{*}}{\partial \mathrm{r}}<0$.

Also, using $\left(I C_{s p}\right)$ and the previous result, it follows that $\frac{\partial \beta^{*}}{\partial \sigma^{2}}<0$ and $\frac{\partial \beta^{*}}{\partial r}<0$. 


\section{APPENDIX B.}

TABLE B1. Linear panel regressions for principals’ fixed pay and share offers in the noise treatment with respect to Others’ Risk Attitudes.

All Periods First Contract Only

\begin{tabular}{ccccc} 
Dependent variables & Fixed pay & Share & Fixed pay & Share \\
\hline Constant & $109.231^{* * *}$ & $60.053^{* * *}$ & $107.500^{* * *}$ & $61.250^{* * *}$ \\
& $(5.432)$ & $(2.134)$ & $(6.122)$ & $(2.319)$ \\
Others' Risk Aversion & 11.527 & -2.870 & $14.545^{*}$ & 2.977 \\
\hline $\mathrm{N}$ & $(7.949)$ & $(2.875)$ & $(7.878)$ & $(3.258)$ \\
\hline $\mathrm{R}^{2}$ & 148 & 148 & 46 & 46 \\
$\mathrm{Prob}>\chi^{2}$ & 0.018 & 0.010 & 0.069 & 0.019 \\
& 0.145 & 0.318 & 0.048 & 0.365
\end{tabular}

*** Significant at the 0.01 level; ** at the 0.05 level; * at the 0.1 level. Robust standard errors are in parentheses.

Others' Risk Aversion is a variable that takes value 1 if the principal believes others to be risk averse and value 0 otherwise. In our regression analysis, we do not separate non-risk-averse beliefs between risk-neutral and risk-seeking beliefs given the very low number ( $n=4$ ) of principals categorizing others as risk seeking.

TABLE B2. Probit panel regression for agent's acceptance decision.

\begin{tabular}{cccc}
\hline \hline & \multicolumn{3}{c}{ Accepted Dummy } \\
\hline Constant & $-0.638^{* *}$ & -0.278 & $-3.023^{* * *}$ \\
& $(0.283)$ & $(0.302)$ & $(0.670)$ \\
Noise Treatment Dummy & -0.176 & 0.048 & -0.103 \\
Contract offer & $(0.197)$ & $(0.166)$ & $(0.213)$ \\
Fixed pay & & - & $0.024^{* * *}$ \\
& $0.016^{* * *}$ & & $(0.005)$ \\
Production share & $(0.003)$ & $0.025^{* * *}$ & $0.043^{* * *}$ \\
N & - & $(0.008)$ & $(0.009)$ \\
\hline Log pseudolikelihood & 318 & 318 & 318 \\
Prob $>\chi^{2}$ & -157.816 & -167.290 & -137.637 \\
& $<0.001$ & $<0.001$ & $<0.001$ \\
\hline *** Significant at the 0.01 level; $* *$ at the 0.05 level; * at the 0.1 level. Robust standard errors are in parentheses.
\end{tabular}


TABLE B3. Linear panel regressions for agent's effort (number of completed tables and time spent on the work task) and principals' earnings.

\begin{tabular}{|c|c|c|c|c|c|c|c|c|}
\hline \multirow[b]{2}{*}{ Constant } & \multicolumn{2}{|c|}{$\begin{array}{c}\text { Agents } \\
\text { Number of } \\
\text { completed tables }\end{array}$} & \multicolumn{2}{|c|}{$\begin{array}{l}\text { Agents } \\
\text { Time spent on } \\
\text { the work task } \\
\text { (in minutes) }\end{array}$} & \multicolumn{2}{|c|}{$\begin{array}{c}\text { Agents } \\
\text { Productivity } \\
\text { (Production / Work time) }\end{array}$} & \multicolumn{2}{|c|}{$\begin{array}{l}\frac{\text { Principals' }}{\text { Earnings }} \\
\text { (in cents) }\end{array}$} \\
\hline & $\begin{array}{c}6.805^{* * *} \\
(1.179)\end{array}$ & $\begin{array}{l}3.818^{* *} \\
(1.906)\end{array}$ & $\begin{array}{l}-2.173 \\
(5.186)\end{array}$ & $\begin{array}{c}-1.868 * * \\
(5.184)\end{array}$ & $\begin{array}{l}-0.406 \\
(0.319)\end{array}$ & $\begin{array}{l}-0.332 \\
(0.317)\end{array}$ & $\begin{array}{l}-230.579 \\
(173.250)\end{array}$ & $\begin{array}{l}-214.343 \\
(164.523)\end{array}$ \\
\hline $\begin{array}{c}\text { Noise Treatment } \\
\text { Dummy }\end{array}$ & $\begin{array}{c}2.320^{* * * *} \\
(0.822)\end{array}$ & $\begin{array}{c}2.026^{* *} \\
(0.818)\end{array}$ & $\begin{array}{l}0.439 * * \\
(0.216)\end{array}$ & $\begin{array}{c}0.453^{* *} \\
(0.222)\end{array}$ & $\begin{array}{c}0.029 * * \\
(0.13)\end{array}$ & $\begin{array}{c}0.021 \\
(0.014)\end{array}$ & $\begin{array}{c}23.702 * * * \\
(7.534)\end{array}$ & $\begin{array}{c}16.969 * * \\
(7.326)\end{array}$ \\
\hline Production share & $\begin{array}{c}0.044^{* *} \\
(0.017)\end{array}$ & $\begin{array}{c}0.046^{* * *} \\
(0.017)\end{array}$ & $\begin{array}{c}0.012 \\
(0.009)\end{array}$ & $\begin{array}{c}0.011 \\
(0.009)\end{array}$ & $\begin{array}{c}0.001 * \\
(0.0006)\end{array}$ & $\begin{array}{l}0.001 * \\
(0.006)\end{array}$ & - & - \\
\hline$\underline{\text { Ability measures }}$ & $\begin{array}{c}0.419 \\
(0.444)\end{array}$ & - & $\begin{array}{c}0.457 \\
(0.329)\end{array}$ & - & $\begin{array}{c}0.075^{* * *} \\
(0.018)\end{array}$ & - & $\begin{array}{c}56.825 * * * \\
(17.925)\end{array}$ & - \\
\hline $\begin{array}{l}\text { Self-reported } \\
\text { skills }\end{array}$ & - & $\begin{array}{l}0.666^{*} \\
(0.344)\end{array}$ & - & $\begin{array}{l}-0.044 \\
(0.185)\end{array}$ & - & $\begin{array}{c}0.037 * * * \\
(0.011)\end{array}$ & - & $\begin{array}{c}25.126^{* * *} \\
(5.526)\end{array}$ \\
\hline $\mathrm{N}$ & 239 & 239 & 239 & 239 & $236^{25}$ & 236 & 239 & 239 \\
\hline $\mathrm{R}^{2}$ & 0.060 & 0.075 & 0.038 & 0.024 & 0.114 & 0.119 & 0.104 & 0.140 \\
\hline Prob $>\chi^{2}$ & 0.004 & $<0.001$ & 0.125 & 0.151 & 0.001 & 0.001 & 0.001 & 0.001 \\
\hline
\end{tabular}

*** Significant at the 0.01 level; ** at the 0.05 level; * at the 0.1 level. Robust standard errors are in parentheses.

\footnotetext{
${ }^{25}$ In three cases, agents did not spend any time on the work task.
} 
TABLE B4. Linear (panel for the first two columns) regressions for agent's production across treatments as a function of the history of shocks. ${ }^{26}$

\begin{tabular}{cc|c|c}
\hline \hline & In Loss Domain & Not in Loss Domain & First production period \\
\hline \multicolumn{1}{c|}{ Constant } & $1.852(2.052)$ & $1.845(1.776)$ & $0.694(1.848)$ \\
Noise Treatment Dummy & $2.904^{* * *}(0.943)$ & $1.055(0.771)$ & $1.565^{* *}(0.747)$ \\
$\begin{array}{c}\text { Contract offer } \\
\text { Production share }\end{array}$ & $0.031^{*}(0.018)$ & $0.029^{*}(0.016)$ & $0.043(0.028)$ \\
Ability measures & & & \\
Self-reported skills & $0.904^{* *}(0.378)$ & $0.925^{* * *}(0.318)$ & $0.880^{* * *}(0.302)$ \\
\hline $\mathrm{N}$ & 156 & 206 & 100 \\
$\mathrm{R}^{2}$ & 0.147 & 0.086 & 0.134 \\
Prob $>\chi^{2}$ & $<0.001$ & 0.002 & $<0.001$ \\
\hline
\end{tabular}

Note that we do not compare treatments for subjects who were not loss averse since we were only able to recruit back 21 subjects who participated in the baseline, among which only 3 were not loss averse (and one of them never played the role of agent).

${ }^{26}$ Results are robust to controlling for fixed pay instead of controlling for production shares. Similar results are also obtained when using "self-reported math skills" as a control for ability. 


\section{APPENDIX C.}

TABLE C1. Linear panel regressions for principals' fixed pay and share offers in the noise treatment controlling for principals' social preferences.

\begin{tabular}{|c|c|c|c|c|}
\hline & \multicolumn{2}{|c|}{ Fixed pay } & \multicolumn{2}{|c|}{ Share } \\
\hline Constant & $\begin{array}{c}89.352 * * * \\
(2.457)\end{array}$ & $\begin{array}{c}88.152 * * * \\
(2.970)\end{array}$ & $\begin{array}{c}42.341^{* * * *} \\
(1.155)\end{array}$ & $\begin{array}{c}41.192 * * * \\
(1.377)\end{array}$ \\
\hline Noise Treatment Dummy & $\begin{array}{l}6.560 * \\
(3.503)\end{array}$ & $\begin{array}{l}7.979 * * \\
(3.663)\end{array}$ & $\begin{array}{c}-3.924 * * \\
(1.664)\end{array}$ & $\begin{array}{c}-3.538 * * \\
(1.683)\end{array}$ \\
\hline $\begin{array}{l}\text { Principals’ social } \\
\text { preferences }\end{array}$ & & & & \\
\hline Egalitarian Dummy & $\begin{array}{c}24.673^{* * *} \\
\quad(7.487)\end{array}$ & - & $\begin{array}{c}3.799 \\
(3.987)\end{array}$ & - \\
\hline Ahead averse Dummy & - & $\begin{array}{c}10.194 * * \\
(4.156)\end{array}$ & - & $\begin{array}{c}5.405 * * * \\
(1.540)\end{array}$ \\
\hline Behind averse Dummy & - & $\begin{array}{l}-2.140 \\
(4.583)\end{array}$ & - & $\begin{array}{c}0.169 \\
(1.923)\end{array}$ \\
\hline $\mathrm{N}$ & 318 & 318 & 318 & 318 \\
\hline $\begin{array}{c}\mathrm{R}^{2} \\
\text { Prob }>\chi^{2}\end{array}$ & $\begin{array}{c}0.036 \\
<0.001\end{array}$ & $\begin{array}{l}0.026 \\
0.024\end{array}$ & $\begin{array}{l}0.018 \\
0.050\end{array}$ & $\begin{array}{c}0.037 \\
<0.001\end{array}$ \\
\hline
\end{tabular}


TABLE C2. Probit panel regression for agent's acceptance decision controlling for agents' social preferences.

\begin{tabular}{|c|c|c|}
\hline \multirow[b]{2}{*}{ Constant } & \multicolumn{2}{|c|}{ Accepted Dummy } \\
\hline & $\begin{array}{c}-2.993 * * * \\
(0.690)\end{array}$ & $\begin{array}{c}-2.931 * * * \\
(0.688)\end{array}$ \\
\hline Noise Treatment Dummy & $\begin{array}{l}-0.103 \\
(0.212)\end{array}$ & $\begin{array}{l}-0.124 \\
(0.237)\end{array}$ \\
\hline \multicolumn{3}{|l|}{ Contract offer } \\
\hline Fixed pay & $\begin{array}{c}0.024^{* * *} \\
(0.005)\end{array}$ & $\begin{array}{c}0.024 * * * \\
(0.005)\end{array}$ \\
\hline Production share & $\begin{array}{c}0.043^{* * *} \\
(0.009)\end{array}$ & $\begin{array}{c}0.043^{* * *} \\
(0.008)\end{array}$ \\
\hline \multicolumn{3}{|l|}{ Agents' social preferences } \\
\hline Egalitarian Dummy & $\begin{array}{l}-0.340 \\
(0.270)\end{array}$ & - \\
\hline Ahead averse Dummy & - & $\begin{array}{c}-0.154 \\
(0.245)\end{array}$ \\
\hline Behind averse Dummy & - & $\begin{array}{l}-0.004 \\
(0.213)\end{array}$ \\
\hline $\mathrm{N}$ & 318 & 318 \\
\hline Log pseudolikelihood & -137.369 & -137.443 \\
\hline Prob $>\chi^{2}$ & $<0.001$ & $<0.001$ \\
\hline
\end{tabular}


TABLE C3. Linear panel regressions for agent's production controlling for agents' social preferences.

\begin{tabular}{|c|c|c|c|c|c|c|}
\hline \multirow[b]{2}{*}{ Constant } & \multicolumn{6}{|c|}{ Production } \\
\hline & $\begin{array}{c}-5.762 \\
(3.676)\end{array}$ & $\begin{array}{c}-5.904 \\
(1.048)\end{array}$ & $\begin{array}{c}-5.510 \\
(3.553)\end{array}$ & $\begin{array}{l}-5.696 \\
(3.538)\end{array}$ & $\begin{array}{c}-5.752 \\
(3.564)\end{array}$ & $\begin{array}{l}-5.913^{*} \\
(3.552)\end{array}$ \\
\hline Noise Treatment Dummy & $\begin{array}{c}0.376 * * \\
(0.157)\end{array}$ & $\begin{array}{c}0.382 * * \\
(0.157)\end{array}$ & $\begin{array}{c}0.370 * * \\
(0.152)\end{array}$ & $\begin{array}{c}0.378 * * \\
(0.152)\end{array}$ & $\begin{array}{c}0.294 * * \\
(0.154)\end{array}$ & $\begin{array}{c}0.300 * * \\
(0.154)\end{array}$ \\
\hline \multicolumn{7}{|l|}{ Contract offer } \\
\hline Production share & $\begin{array}{l}0.013 * \\
(0.008)\end{array}$ & $\begin{array}{l}0.014 * \\
(0.008)\end{array}$ & $\begin{array}{l}0.013 * \\
(0.007)\end{array}$ & $\begin{array}{l}0.014^{*} \\
(0.008)\end{array}$ & $\begin{array}{l}0.014 * \\
(0.007)\end{array}$ & $\begin{array}{l}0.015^{*} \\
(0.008)\end{array}$ \\
\hline \multicolumn{7}{|l|}{$\underline{\text { Ability measures }}$} \\
\hline First table correct & - & - & $\begin{array}{c}0.651 * * * \\
(0.170)\end{array}$ & $\begin{array}{c}0.646^{* * *} \\
(0.167)\end{array}$ & - & - \\
\hline Self-reported skills & - & - & - & - & $\begin{array}{c}0.358 * * * \\
(0.124)\end{array}$ & $\begin{array}{c}0.363 * * * \\
(0.125)\end{array}$ \\
\hline \multicolumn{7}{|l|}{$\frac{\text { Agents' social }}{\text { preferences }}$} \\
\hline Egalitarian Dummy & $\begin{array}{l}-0.274 \\
(0.247)\end{array}$ & - & $\begin{array}{l}-0.235 \\
(0.237)\end{array}$ & - & $\begin{array}{l}-0.286 \\
(0.242)\end{array}$ & - \\
\hline Ahead averse Dummy & - & $\begin{array}{l}-0.134 \\
(0.209)\end{array}$ & - & $\begin{array}{l}-0.085 \\
(0.195)\end{array}$ & - & $\begin{array}{l}-0.138 \\
(0.207)\end{array}$ \\
\hline Behind averse Dummy & - & $\begin{array}{l}-0.216 \\
(0.232)\end{array}$ & - & $\begin{array}{l}-0.231 \\
(0.227)\end{array}$ & - & $\begin{array}{l}-0.232 \\
(0.231)\end{array}$ \\
\hline $\mathrm{N}$ & 239 & 239 & 239 & 239 & 239 & 239 \\
\hline $\mathrm{R}^{2}$ & 0.048 & 0.047 & 0.113 & 0.112 & 0.109 & 0.109 \\
\hline Prob $>\chi^{2}$ & 0.046 & 0.045 & $<0.001$ & $<0.001$ & 0.002 & 0.003 \\
\hline
\end{tabular}

*** Significant at the 0.01 level; ** at the 0.05 level; * at the 0.1 level. Robust standard errors are in parentheses. 
TABLE C4. Linear panel regressions for agent's effort (number of completed tables and time spent on the work task) and principals' earnings controlling for agents' social preferences. ${ }^{27}$

\begin{tabular}{|c|c|c|c|c|c|c|c|c|}
\hline \multirow[b]{2}{*}{ Constant } & \multicolumn{2}{|c|}{$\begin{array}{c}\frac{\text { Agents }}{\text { Number }} \\
\text { of completed tables }\end{array}$} & \multicolumn{2}{|c|}{$\begin{array}{l}\text { Agents } \\
\text { Time spent on } \\
\text { the work task } \\
\text { (in minutes) }\end{array}$} & \multicolumn{2}{|c|}{$\begin{array}{c}\quad \underline{\text { Agents }} \\
\text { Productivity } \\
\text { (Production } \\
\text { / Work time) }\end{array}$} & \multicolumn{2}{|c|}{$\begin{array}{l}\frac{\text { Principals' }}{\text { Earnings }} \\
\text { (in cents) }\end{array}$} \\
\hline & $\begin{array}{l}3.800^{* *} \\
(1.913)\end{array}$ & $\begin{array}{l}3.742 * \\
(.922)\end{array}$ & $\begin{array}{l}-2.119 \\
(5.193)\end{array}$ & $\begin{array}{l}-2.502 \\
(5.298)\end{array}$ & $\begin{array}{l}-0.361 \\
(0.313)\end{array}$ & $\begin{array}{l}-0.362 \\
(0.314)\end{array}$ & $\begin{array}{l}-238.946 \\
(159.406)\end{array}$ & $\begin{array}{l}-222.941 \\
(164.705)\end{array}$ \\
\hline $\begin{array}{c}\text { Noise Treatment } \\
\text { Dummy }\end{array}$ & $\begin{array}{c}2.052 * * \\
(0.821)\end{array}$ & $\begin{array}{c}2.110^{* * * *} \\
(0.819)\end{array}$ & $\begin{array}{l}0.463 * * \\
(0.223)\end{array}$ & $\begin{array}{l}0.474 * * \\
(0.228)\end{array}$ & $\begin{array}{c}0.022 \\
(0.014)\end{array}$ & $\begin{array}{l}0.022^{*} \\
(0.013)\end{array}$ & $\begin{array}{c}18.265^{* *} \\
(7.195)\end{array}$ & $\begin{array}{c}17.750 * * \\
(7.408)\end{array}$ \\
\hline \multicolumn{9}{|l|}{$\underline{\text { Contract offer }}$} \\
\hline Production share & $\begin{array}{c}0.047^{* * *} \\
(0.018)\end{array}$ & $\begin{array}{c}0.049 * * * \\
(0.018)\end{array}$ & $\begin{array}{c}0.012 \\
(0.009)\end{array}$ & $\begin{array}{c}0.015 \\
(0.010)\end{array}$ & $\begin{array}{c}0.001^{*} \\
(0.0006)\end{array}$ & $\begin{array}{c}0.001^{*} \\
(0.0006)\end{array}$ & - & - \\
\hline \multicolumn{9}{|l|}{$\underline{\text { Ability measures }}$} \\
\hline Self-reported skills & $\begin{array}{l}0.664^{* *} \\
(0.343)\end{array}$ & $\begin{array}{l}0.676^{* *} \\
(0.345)\end{array}$ & $\begin{array}{l}-0.045 \\
(0.185)\end{array}$ & $\begin{array}{c}0.043 \\
(0.183)\end{array}$ & $\begin{array}{c}0.037 * * * \\
(0.011)\end{array}$ & $\begin{array}{l}0.037 * * * \\
(0.0011)\end{array}$ & $\begin{array}{l}25.019 * * * \\
(5.587)\end{array}$ & $\begin{array}{l}25.418^{* * *} \\
(5.628)\end{array}$ \\
\hline \multicolumn{9}{|l|}{$\underline{\text { Social preferences }}$} \\
\hline Egalitarian Dummy & $\begin{array}{l}-0.515 \\
(0.547)\end{array}$ & - & $\begin{array}{l}-0.400 \\
(0.269)\end{array}$ & - & $\begin{array}{l}-0.048 \\
(0.034)\end{array}$ & - & $\begin{array}{c}-79.811^{* * *} \\
(19.764)\end{array}$ & 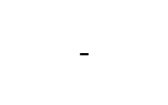 \\
\hline Ahead averse Dummy & - & $\begin{array}{l}-0.105 \\
(0.459)\end{array}$ & - & $\begin{array}{l}-0.350 \\
(0.267)\end{array}$ & - & $\begin{array}{l}-0.010 \\
(0.019)\end{array}$ & - & $\begin{array}{l}-25.997 * \\
(14.102)\end{array}$ \\
\hline Behind averse Dummy & - & $\begin{array}{l}-0.722 \\
(0.580)\end{array}$ & - & $\begin{array}{l}-0.341 \\
(0.293)\end{array}$ & - & $\begin{array}{l}-0.019 \\
(0.021)\end{array}$ & - & $\begin{array}{l}-27.559 * \\
(14.819)\end{array}$ \\
\hline $\mathrm{N}$ & 239 & 239 & 239 & 239 & 236 & 236 & 239 & 239 \\
\hline $\mathrm{R}^{2}$ & 0.079 & 0.084 & 0.028 & 0.023 & 0.135 & 0.128 & 0.170 & 0.162 \\
\hline Prob $>\chi^{2}$ & 0.002 & 0.001 & 0.155 & 0.217 & $<0.001$ & 0.001 & $<0.001$ & $<0.001$ \\
\hline
\end{tabular}

*** Significant at the 0.01 level; ** at the 0.05 level; * at the 0.1 level. Robust standard errors are in parentheses.

${ }^{27}$ Results are reported for the "self-reported skills" ability measure but are robust to using "first table correct" or no controls for ability measures. Principals' earnings are compared only for the cases in which the agent accepted the principal's offer. 


\section{APPENDIX D (For Online Publication)}

\section{D.1. Risk attitudes elicitation}

\section{Own risk attitudes (Instructions)}

In this part of the experiment you will be asked to make a series of choices in decision problems. How much you receive will depend partly on chance and partly on the choices you make. The decision problems are not designed to test you. What we want to know is what choices you would make in them. The only right answer is what you really would choose. For each line in the table on the right, please state whether you prefer option A or option B. Notice that there are a total of 10 lines in the table but just one line will be randomly selected for payment. Each line is equally likely to be chosen, so you should pay equal attention to the choice you make in every line. At the end of the experiment, a number between 1 and 10 will be randomly selected by the computer. This number determines which line is going to be paid. Your earnings for the selected line depend on which option you chose in that line: option A or option B. To determine your earnings, Then, a second number between 1 and 10 will be randomly selected by the computer. This number is then compared with the numbers in the line and option selected (see the table below):

* If you selected option A and the second number shows up in the upper row you earn $\$ 2.00$. If the number shows up in the upper row you earn $\$ 1.60$.

* If you selected option B and the second number shows up in the lower row you earn \$3.85. If the number shows up in the lower row you earn $\$ 0.10$.

TABLE D1. The ten binary lottery choices (Holt and Laury, 2002).

\begin{tabular}{|c|c|c|}
\hline Line & OPTION A & OPTION B \\
\hline 1 & $1 / 10$ of $\$ 2.00,9 / 10$ of $\$ 1.60$ & $1 / 10$ of $\$ 3.85,9 / 10$ of $\$ 0.10$ \\
\hline 2 & $2 / 10$ of $\$ 2.00,8 / 10$ of $\$ 1.60$ & $2 / 10$ of $\$ 3.85,8 / 10$ of $\$ 0.10$ \\
\hline 3 & $3 / 10$ of $\$ 2.00,7 / 10$ of $\$ 1.60$ & $3 / 10$ of $\$ 3.85,7 / 10$ of $\$ 0.10$ \\
\hline 4 & $4 / 10$ of $\$ 2.00,6 / 10$ of $\$ 1.60$ & $4 / 10$ of $\$ 3.85,6 / 10$ of $\$ 0.10$ \\
\hline 5 & $5 / 10$ of $\$ 2.00,5 / 10$ of $\$ 1.60$ & $5 / 10$ of $\$ 3.85,5 / 10$ of $\$ 0.10$ \\
\hline 6 & $6 / 10$ of $\$ 2.00,4 / 10$ of $\$ 1.60$ & $6 / 10$ of $\$ 3.85,4 / 10$ of $\$ 0.10$ \\
\hline 7 & $7 / 10$ of $\$ 2.00,3 / 10$ of $\$ 1.60$ & $7 / 10$ of $\$ 3.85,3 / 10$ of $\$ 0.10$ \\
\hline 8 & $8 / 10$ of $\$ 2.00,2 / 10$ of $\$ 1.60$ & $8 / 10$ of $\$ 3.85,2 / 10$ of $\$ 0.10$ \\
\hline 9 & $9 / 10$ of $\$ 2.00,1 / 10$ of $\$ 1.60$ & $9 / 10$ of $\$ 3.85,1 / 10$ of $\$ 0.10$ \\
\hline 10 & $10 / 10$ of $\$ 2.00,0 / 10$ of $\$ 1.60$ & $10 / 10$ of $\$ 3.85,0 / 10$ of $\$ 0.10$ \\
\hline
\end{tabular}

\section{Others' risk attitudes (Instructions)}

Now, you will have to guess the decisions in the previous part of another subject chosen at random in this experiment. To do so, you will have to select "Option A" or "Option B" on each of the following 10 rows. At the end of the experiment, the computer will select one of you at random. Then, the computer will select randomly the decision table of another subject in the previous part. We will pay the selected guesser $\$ 1.00$ for each row in which the guess matches the other subject's decision. 


\section{D.2. Social preferences elicitation}

We elicited social preferences à la Bartling et al. (2009) by asking subjects to make four choices between two possible allocations of money between themselves and another anonymous subject with whom they were randomly matched. The allocation decisions are described in the Table D2. Option A always yielded an even distribution of money (\$2 to the self and the other subject). Option B yielded uneven payoffs: (\$2, \$1), (3\$, \$1), (2\$, \$4), and (3\$, \$5) in Decisions 1, 2, 3 and 4, respectively. We classify subjects following Bartling et al. (2009) into four social preferences categories: prosocial, costly prosocial, envious and costly envious. Prosocial types prefer to distribute income equal distributions even when they have the possibility to earn more than the other subjects (in which case subjects are characterized as costly prosocial). Envy types dislike earning less than the other subject and choose Option A in the last two decisions even if it implies a lower payoff to themselves (in which case subjects are characterized as costly envious). Following Bartling et al. (2009), we characterize subjects as either ahead (behind) averse if they were both prosocial and costly prosocial (envious and costly envious). Egalitarian subjects were defined as being both ahead and behind averse.

\section{Instructions:}

You will be asked to make a series of choices in decision problems. For each line in the table below (Table D2), please state whether you prefer Option A or Option B. Notice that there are a total of 4 lines in the table but just one line will be randomly selected for payment. Each line is equally likely to be chosen, so you should pay equal attention to the choice you make in every line. After you have made all your decisions a number between 1 and 4 will be randomly selected by the computer. This number determines which line is going to be paid. Your earnings for the selected line depend on which option you chose: if you chose Option A in that line, you will receive $\$ 2$ and the other participant who will be matched with you will also receive $\$ 2$. If you chose Option B in that line, you and the other participant will receive earnings as indicated in the table for that specific line. For example, if you chose B in line 2 and this line is selected for payment, you will receive \$3 and the other participant will receive $\$ 1$. Similarly, if you chose $\mathrm{B}$ in line 3 and this line is selected for payment, you will receive \$2 and the other participant will receive $\$ 4$. Note that the other participant will never be informed of your personal identity and you will not be informed of the other participant's personal identity. After you have made all your decisions, the computer will randomly draw a number to determine which line is going to be paid. Then the computer will randomly and anonymously match you with another participant in the experiment. While matching you with another participant, the computer will also randomly determine whose decision to implement. If the computer chooses your decision to implement, then the earnings to you and the other participant will be determined according to your choice of A or B. If the computer chooses the other participant decision to implement, then the earnings will be determined according to the other participant choice of A or B. 
TABLE D2. Social preferences elicitation (Bartling et al. 2009).

\begin{tabular}{ccc}
\hline \hline Decision & $\begin{array}{c}\text { Option A } \\
\text { Payoff self, Payoff other }\end{array}$ & $\begin{array}{c}\text { Option B } \\
\text { Payoff self, Payoff other }\end{array}$ \\
\hline 1 & $\$ 2, \$ 2$ & $\$ 2, \$ 1$ \\
2 & $\$ 2, \$ 2$ & $\$ 3, \$ 1$ \\
3 & $\$ 2, \$ 2$ & $\$ 2, \$ 4$ \\
4 & $\$ 2, \$ 2$ & $\$ 3, \$ 5$ \\
\hline
\end{tabular}

\section{D.3. Risk attitudes elicitation in the real-effort task}

We presented subjects with the work task environment detailed in Section 3. We described both the baseline and the noise treatments which were referred to as the certain and random scenarios. In the certain [random] scenario the earnings of the subjects were computed as for the agents in our baseline [noise] treatment. For each scenario, we used a strategy-method approach and asked subjects to choose, for a given share of production, the minimum fixed pay they would be willing to accept to work on the summation task for 10 minutes instead of receiving the outside payment of $150 \$$ to browse the Internet (see Table D3). Note that we randomized the order of the scenarios so that 30 subjects started by considering the case of the certain scenario whereas 30 subjects started by considering the case of the random scenario. Subjects had to make a total of eleven minimum fixed pay decisions per scenario since eleven different values of shares of production were considered: $\{0 \%, 10 \%, \ldots, 100 \%\}$. After subjects made their minimum fixed pay decisions, an offer (a fixed pay between 0 and 200 and a share of production belonging to the eleven possible values previously considered) was randomly selected for each of the two scenarios. For each scenario, the randomly selected offer was considered to be accepted (rejected) by a subject if the proposed fixed pay was higher or equal to (lower than) the subject's minimum fixed pay for the randomly selected share of production. Thereafter, a 10minute period started for the corresponding scenario (certain or random) where the subject could produce on the task if the randomly selected offer had been accepted or simply browse the internet if the randomly selected offer had been rejected.

The design of this experiment was aimed at eliciting risk attitudes in the real-effort task and not at studying production. As a result, the risk-elicitation study differed in a number of important dimensions from the original study. For example, the risk-elicitation study uses a within-subject design for which subjects had to consider both the certain and random scenarios instead of being randomly assigned to only one (as was the case in the original study). This was done to mimic risk elicitation in lottery settings where choices involving varying degrees of risk are jointly presented to subjects (e.g. Holt and Laury, 2002). Second, offers were selected at random and thus did not mimic the pattern of offers of human principals of our original experiments. Third, only a subset of offers were finally accepted so that the sample size ( $\mathrm{n}=22$ [20] for the case in which the certain scenario was considered first [second]) was considerably smaller than in our original study. 
In this setting, we categorize subjects as risk averse if they ask, on average, a higher minimum fixed pay in the random scenario than in the certain scenario. ${ }^{28}$ Using this criterion, $65 \%$ of the subjects were classified as risk averse which is similar to the proportion of subjects who were classified as risk averse by Holt and Laury (66\%). This proportion does not significantly differ either from the proportion of subjects that we classified as risk averse in our original sample using the Holt and Laury risk-elicitation technique ( $p$-value $=0.255$ for the proportion test).

On average, subjects asked for a minimum fixed pay of 118.54 in the random scenario compared to $109.9 \$$ in the baseline (Wilcoxon signed-rank test, p-value $=0.06$ ). Also, the realeffort task risk elicitation led to a classification of risk averse and risk seeking subjects which coincides with the Holt and Laury test for $64 \%$ of our subjects. ${ }^{29}$

TABLE D3. Elicitation of minimum fixed pay for each of eleven possible values of the share of production (certain scenario case).

\begin{tabular}{|l|l|}
\hline \multicolumn{1}{|c|}{ CERTAIN SCENARIO } & Fixed pay \\
\hline If the share is $\mathbf{0 \%}$ the minimum fixed pay you are willing to accept is: & \\
\hline If the share is $\mathbf{1 0 \%}$ the minimum fixed pay you are willing to accept is: & \\
\hline If the share is $\mathbf{2 0} \%$ the minimum fixed pay you are willing to accept is: & \\
\hline If the share is $\mathbf{3 0 \%}$ the minimum fixed pay you are willing to accept is: & \\
\hline If the share is $\mathbf{4 0 \%}$ the minimum fixed pay you are willing to accept is: & \\
\hline If the share is $\mathbf{5 0 \%}$ the minimum fixed pay you are willing to accept is: & \\
\hline If the share is $\mathbf{6 0} \%$ the minimum fixed pay you are willing to accept is: & \\
\hline If the share is $\mathbf{7 0 \%}$ the minimum fixed pay you are willing to accept is: & \\
\hline If the share is $\mathbf{8 0} \%$ the minimum fixed pay you are willing to accept is: & \\
\hline If the share is $\mathbf{9 0 \%}$ the minimum fixed pay you are willing to accept is: & \\
\hline If the share is $\mathbf{1 0 0} \%$ the minimum fixed pay you are willing to accept is: & \\
\hline
\end{tabular}

\footnotetext{
${ }^{28}$ There were no cases of ties. Our results are robust to considering median minimum fixed pay as a classification criterion. Also, using only a subset of the eleven shares of production does not affect the qualitative nature of our findings.

${ }^{29}$ We assess whether this result can be only explained by chance by testing whether the proportion of correct classifications was significantly different from $50 \%$ and report a p-value equal to 0.07 .
} 


\section{D.4. Loss aversion elicitation (Instructions)}

For each of the six lotteries described below, you have to decide whether to accept or reject it. Mark the corresponding column (either Accept or Reject) with a cross. In this experiment, the gains you make you will be added to your $\$ 13$ show-up fee and the losses you incur will be subtracted from your $\$ 13$ show-up fee.

Once you have made a decision for each of the six lotteries, one of them will be selected at random using a die roll. Then, a coin will be flipped which will determine your final earnings.

Example: After you have made your decisions whether to accept or reject each of the six lotteries, a die is rolled. The die roll is $\mathbf{3}$ in which case lottery \# $\mathbf{3}$ will be played:

“\#3. If the coin turns up heads, then you lose \$3; if the coin turns up tails, you win \$5.”

Then, a coin is flipped. If the coin turns up heads then you will lose \$3 in which case your earnings will be: $13 \$-3 \$=\$ 10$.

If the coin turns up tails then you will win $\$ 5$ in which case your earnings will be: $14 \$+5 \$=$ $\$ 19$.

TABLE D4. Lottery choices for loss aversion elicitation.

\begin{tabular}{|l|l|l|}
\hline \multicolumn{1}{|c|}{ Lottery } & Accept & Reject \\
\hline $\begin{array}{l}\text { \#1. If the coin turns up heads, then you lose \$1; if the coin turns up } \\
\text { tails, you win \$5. }\end{array}$ & & \\
\hline $\begin{array}{l}\text { \#2. If the coin turns up heads, then you lose \$2; if the coin turns up } \\
\text { tails, you win \$5. }\end{array}$ & & \\
\hline $\begin{array}{l}\text { \#3. If the coin turns up heads, then you lose \$3; if the coin turns up } \\
\text { tails, you win \$5. }\end{array}$ & & \\
\hline $\begin{array}{l}\text { \#4. If the coin turns up heads, then you lose \$4; if the coin turns up } \\
\text { tails, you win \$5. }\end{array}$ & & \\
\hline $\begin{array}{l}\text { \#5. If the coin turns up heads, then you lose \$5; if the coin turns up } \\
\text { tails, you win \$5. }\end{array}$ & & \\
\hline $\begin{array}{l}\text { \#6. If the coin turns up heads, then you lose \$6; if the coin turns up } \\
\text { tails, you win \$5. }\end{array}$ & & \\
\hline
\end{tabular}

